\title{
DESENVOLVIMENTO DE MÁQUINA DE MOVIMENTOS CÍCLICOS PARA TESTES BIOMECÂNICOS
}

\section{CARLOS ALBERTO MARINHEIRO}

Dissertação apresentada ao Programa de PósGraduação Interunidades em Bioengenharia Escola de Engenharia de São Carlos, Faculdade de Medicina de Ribeirão Preto, Instituto de Química de São Carlos, da Universidade de São Paulo, para obtenção do título de Mestre em Bioengenharia.

Orientador: Prof. Dr. Celso Hermínio F. Picado

Ribeirão Preto

2002 



\section{Dedicatória:}

A Deus, pelo dom da vida.

À minha esposa Iva Cristina e aos meus filhos Leonardo e Eduardo, pela compreensão que tiveram durante minha ausência física. À minha mãe Luzia, ao meu pai João (in memorian), que sempre indicaram o melhor caminho, e deram o melhor exemplo. 


\section{Agradecimentos:}

Ao Prof. Dr. Celso Hermínio Ferraz Picado, pela paciência, incentivo e colaboração.

Ao Dr. Antonio Carlos Shimano, pelo apoio, pelos ensinamentos, pelas orientações e sugestões que levaram ao êxito este trabalho.

Aos amigos da Oficina de Precisão, Davidson, Otávio, Ednilson, Moacir, Amauri, Paulinho, Gallon e ao Aparecido (Cidão), que construíram, montaram e até inventaram componentes deste projeto.

Aos funcionários do Laboratório de Bioengenharia, Eng. Moro, Luiz Henrique, Francisco (Chico), Teresinha, pela colaboração e amizade.

Para as amigas do Departamento de Ortopedia, Fátima e Elizangela, pelo apoio; e à Rose, pela colaboração nas fotos e filmes do equipamento.

À Janete e à D. Marielza da Bioengenharia de São Carlos, pelo apoio, pela dedicação e eficiência.

Ao amigo Vitor, ao Mestre Marcos Shimano pelo apoio nos desenhos, projetos e organização das apresentações.

Para a Baumer Ortopedia, por intermédio dos amigos José Roberto e Marcos, pela colaboração, fornecendo as próteses e os acessórios para a realização do ensaio e validação da máquina. 
Agradecimento especial:

Ao Laboratório de Bioengenharia da Faculdade de Medicina de Ribeirão Preto, nas pessoas do Prof. Dr. José Baptista P. Paulin e do Prof. Dr. José B. Volpon, pela disponibilidade do laboratório, pelo incentivo e apoio. 


\section{SUMÁRIO}

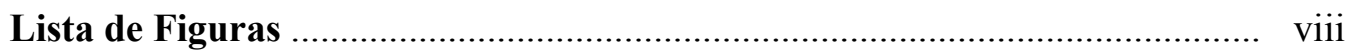

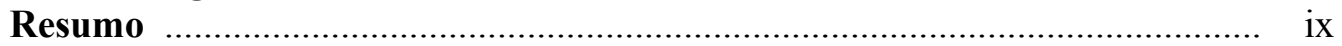

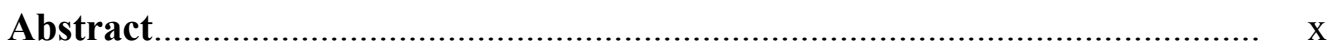

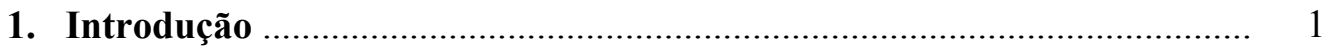

1.1 A Macha Humana .......................................................................... 1

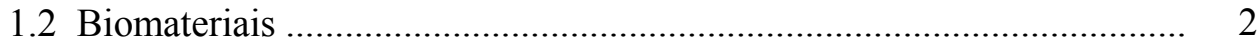

1.2.1 Aspectos históricos .............................................................. 2

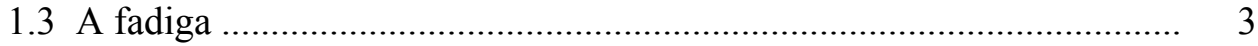

1.3.1 O processo de fadiga ............................................................. 4

1.3.2 A fadiga em implantes metálicos ............................................. 5

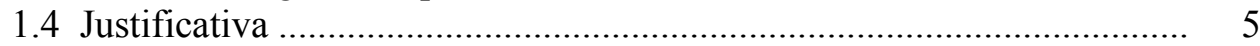

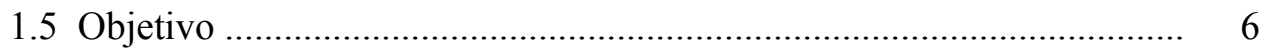

2. Material e Métodos ….......................................................................... 7

2.1 Pré-protótipo ........................................................................... 7

2.2 Protótipo final .............................................................................. 8

2.2.1 Estrutura da Máquina de Ensaio Cíclico - MEC …..................... 8

2.2.2 Sistema de acionamento do movimento ................................... 10

2.2.3 Sistema de transmissão de carga cíclica .................................... 11

2.2.3.1. Dispositivo transmissor da carga ............................... 11

2.2.4 Controle dos ciclos................................................................. 13

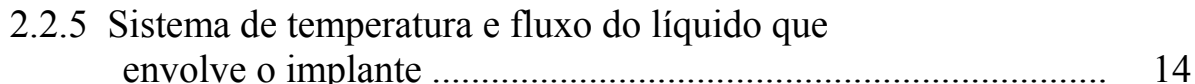

2.2.6 Painel de controle e monitoramento ......................................... 15

3. Validação da máquina de ensaio cíclico …................................................ 18

3.1 Ensaio de fadiga ............................................................................... 18

3.1.1 Controle de calibração da carga aplicada ................................ 18

3.1.2 Recipiente para recepção do componente femoral ................... 20

3.1.3 Fixação da haste femoral ...................................................... 20

3.1.4 Posição da haste femoral ......................................................... 21

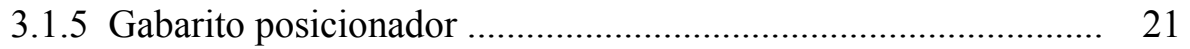

3.1.6 Aplicação da carga ............................................................... 24

3.2 Resultados do teste de fadiga .......................................................... 26

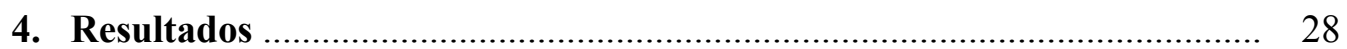

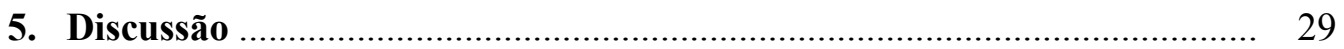


6. Conclusão

7. Anexos

Anexo A - Orçamento da M.T.S. ...................................................... 37

Anexo B - Relatório de acompanhamento diário ........................................ 38

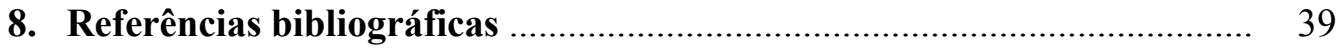




\section{LISTA DE FIGURAS}

Figura 1. Foto do pré-protótipo …..................................................................... 7

Figura 2. Estrutura da Máquina de Ensaio Cíclico.

(a) Mesa superior; (b) Mesa inferior

7

Figura 3. (1) Reforço da mesa superior .............................................................. 9

Figura 4. Máquina de Ensaio Cíclico - MEC …................................................ 9

Figura 5. Mecanismo de movimentos cíclicos .............................................. 10

Figura 6. Parte superior da máquina.

(1) Bases; (2) Braços de alavancas .................................................... 11

Figura 7. Mecanismo de transmissão de carga

(1) Dispositivo de carga; (2) Apoio de polietileno ............................ 12

Figura 8. Dispositivo de transmissão de carga .................................................. 12

Figura 9. Dispositivo de transmissão de carga mostrando as esferas ................ 12

Figura 10. Painel do inversor de freqüência .................................................. 13

Figura 11. Reservatório de soro fisiológico ....................................................... 14

Figura 12. Reservatório de acrílico com soro fisiológico.

(1) Entrada do soro; (2) Saída do soro .......................................... 15

Figura 13. Parte frontal da máquina ............................................................ 16

Figura 14. Painel externo de controle ......................................................... 16

Figura 15. Parte interna do painel de controle .................................................. 17

Figura 16. Sistema de controle da carga

(1) Apoio do braço de alavanca; (2) Molas ....................................... 19

Figura 17. Calibração da carga ............................................................................ 19

Figura 18. Recipiente para fixação da haste da prótese femoral ........................ 20

Figura 19. Inclinação da haste femoral (M-L) .................................................... 21

Figura 20. Inclinação da haste femoral (A-P) ................................................... 21

Figura 21. Gabarito posicionador da haste femoral ........................................... 22

Figura 22. Posicionamento da haste femoral para o ensaio. (1) Guia; (2) Cursor; (3) Alavanca do mecanismo que fixa a haste femoral ........................................................................ 23

Figura 23. Fixação da haste femoral no cimento acrílico .................................. 24

Figura 24. Mecanismo de carga apoiado na prótese femoral ........................... 24

Figura 25. Hastes femorais e cimento, fixados no polietileno .......................... 26

Figura 26. Hastes femorais fixadas no cimento acrílico .................................. 26

Figura 27. Cones de cimento acrílico seccionados .......................................... 27 
MARINHEIRO, C. A. Desenvolvimento de máquina de movimentos cíclicos para testes biomecânicos. São Carlos, 2002. 51 p.

Dissertação (Mestrado) - Escola de Engenharia de São Carlos/Faculdade de Medicina de Ribeirão Preto/Instituto de Química de São Carlos, Universidade de São Paulo.

\section{RESUMO}

O ser humano locomove-se utilizando-se do complexo sistema neuromúsculo-esquelético, o que lhe confere qualidade de vida. Partes do sistema esquelético são passíveis de tratamento ou mesmo de substituição pelo emprego de materiais estranhos ao corpo humano mas que provocam pequena reação biológica e necessitam ser dimensionados de modo a suportar toda tensão resultante do movimento humano. $\mathrm{O}$ objetivo deste trabalho foi desenvolver uma máquina de ensaio cíclico para testes biomecânicos, de implantes utilizados nas cirurgias de reconstrução ósteo-articular, utilizando tecnologia nacional. A máquina possui um sistema de acionamento por meio de um motor trifásico de $2 \mathrm{HP}, 1800 \mathrm{rpm}$; um sistema de transmissão de cargas cíclicas utilizando um eixo excêntrico, que aciona um pistão, que promove o movimento de duas alavancas que transmitem a carga para os componentes a serem ensaiados. Há um inversor de freqüência para controle do número de ciclos do motor, um reservatório de soro fisiológico com um sistema que mantém o soro aquecido entre 36 e $38^{\circ} \mathrm{C}$, e uma bomba hidráulica submersa que mantém o soro em constante movimentação. Foi feito um teste cíclico de fadiga de componente femoral de artroplastia de quadril, com torção, seguindo determinações das normas ISO 7206/89, parte 4 e ASTM F 1612/95, e utilizada para o teste a Prótese Femoral Cimentada Modelo Alpha ${ }^{\circledR}$ da empresa Baumer ${ }^{\circledR}$, haste polida de $150 \mathrm{~mm}$ e off-set de $37,5 \mathrm{~mm}$. Também foi feito um ensaio para verificação de trincas seguindo determinações da Norma ABNT NBR ISO 9583/1997. Durante as 139 horas previstas para o teste de fadiga do componente femoral, a máquina de ensaio não apresentou problemas mecânicos, demonstrando eficiência e o êxito na confecção de uma máquina de ensaios cíclicos para testes biomecânicos.

Palavras chave: Ensaio biomecânico; movimento cíclico; fadiga; biomaterial. 
MARINHEIRO, C. A. Development of machine of cyclic movements for biomechanical tests. São Carlos, 2002. 51 p.

Dissertação (Mestrado) - Escola de Engenharia de São Carlos/Faculdade de Medicina de Ribeirão Preto/Instituto de Química de São Carlos, Universidade de São Paulo.

\begin{abstract}
The human being locomotes using the complex neuro-muscle-skeletal system, what confers him life quality. Parts of the skeletal system can submit to treatment or even to the substitution for the employment of strange materials to the human body but that provoke small biological reaction and they need to be projected in way to support every resulting tension of the human movement. The objective of this work was to develop a machine of cyclic trial for biomechanical tests using national technology. The machine has an activation system by means of a triphasic motor of $2 \mathrm{HP}, 1800 \mathrm{rpm}$; a system of transmission of cyclic loads using an eccentric axis, that activates a piston, that promotes the movement of two levers that transmit the load for the components at be tested. There is a frequency inverter for control of the number of cycles of the motor, a reservoir of physiologic serum with a system that maintains the serum heated up to $36-38^{\circ} \mathrm{C}$, and a submerged hydraulic bomb that maintains the serum in constant movement. It was made a cyclic test of fatigue of femoral component of hip arthroplasty, with torsion, following determinations of the norms ISO 7206/89, part 4 and ASTM F 1612/95, and used for the test the Prosthesis Femoral Cemented Model Alpha ${ }^{\circledR}$ of the company Baumer ${ }^{\circledR}$, polished stem of $150 \mathrm{~mm}$ and off-set of $37,5 \mathrm{~mm}$. It was also made a trial for verification of cracks following determinations of the norm ABNT NBR ISO 9583/1997. During the 139 hours foreseen for the test of fatigue of the femoral component, the trial machine didn't present mechanical problems, demonstrating efficiency and the success in the production of a machine of cyclic trials for biomechanical tests.
\end{abstract}

Keywords: Biomechanical trial; cyclic movement; fatigue; biomaterial. 


\section{INTRODUÇÃO}

\subsection{A marcha humana}

$\mathrm{O}$ andar é uma das principais habilidades do indivíduo e, apesar de sua complexidade, este se caracteriza por movimentos suaves, regulares e repetitivos, com surpreendente eficiência do ponto de vista neuro-músculo-esquelético (VAUGHAN et al., 1996).

A marcha humana é o mecanismo capaz de promover o deslocamento do corpo entre dois pontos de maneira segura e eficiente. A marcha sofre variações individuais de acordo com fatores neurológicos, antropométricos e psicológicos (GREVE, 1999).

Durante o ciclo da marcha, a ação muscular integrada, envolvendo tanto os membros superiores quanto os membros inferiores, transmite tensões cíclicas ao osso (WINTER, 1990; HAMIL et al., 1999).

Tensões de várias intensidades e direções são aplicadas, e todos esses esforços fazem parte do desenvolvimento do corpo humano, uma vez que evitam atrofias musculares e ósseas, e promovem sua manutenção.

O ser humano, em média, dá um milhão de passos por ano (ROSE et al., 1980; NORTHFIELD, 1994).

Quando precisamos auxiliar ou substituir a função de algum osso ou articulação, utilizamos os implantes. Estes materiais deverão ser dimensionados para receber toda tensão resultante do movimento humano, com toda sua complexidade. 


\subsection{Biomateriais}

Segundo Williams (1987), biomaterial é uma substância farmacologicamente inerte, idealizada para implantes ou incorporação por um sistema vivo com a finalidade de substituir matéria viva que deixou de ter sua função, podendo ou não servir como veículo, matriz, suporte ou estimulador para o crescimento de novo tecido.

A utilização do biomaterial como implante do corpo humano, remonta muitos séculos passados (ROCKWOOD et al., 1993; DANDY, 2000).

\subsubsection{Aspectos históricos}

Os primeiros registros do emprego de materiais metálicos para aplicações cirúrgicas datam do século XVI, onde relatam a reparação de um palato partido com uma placa de ouro, por Petronius em 1565 (LOPES, 1993). Até o final do século XIX várias tentativas de introduzir materiais metálicos no interior do corpo humano foram em sua maioria frustradas.

Ludwigson (1964) apud Fraker et al., (1977), estabelece o histórico da evolução dos implantes metálicos em:

- Antes de 1875, eram utilizados metais puros, como por exemplo o ouro, a prata e o cobre. No período de 1875 a 1925 foi onde as cirurgias começaram a ter mais êxito.

口 De 1925 até os dias de hoje as ligas metálicas passaram a dar melhores propriedades físicas aos materiais.

O surgimento das ligas, foi motivado pela necessidade de se conseguir materiais metálicos de elevada resistência mecânica, e também resistentes à corrosão. Em 1926 aparecem os implantes de aço inoxidável austenítico, e em 1936 surgem as ligas à base de cromo-cobalto (VENABLE, 1947, LOPES, 1993). O titânio e sua ligas começaram a ser utilizados na década de 60 (LOPES, 1993; ROSA et al., 2001).

Um grande desafio da cirurgia ortopédica é a busca de implantes para fixar fraturas ou substituir partes do esqueleto, feitos de materiais que conciliem bom 
desempenho mecânico e conveniente compatibilidade com o organismo (CHOHFI et al., 1997).

A qualidade dos implantes sempre foi considerada um fator fundamental para a prescrição cirúrgica, por parte dos profissionais da área médica. De nada adianta ter uma técnica cirúrgica de boa performance se o material utilizado não atender os requisitos básicos.

A preocupação é geral; do paciente, do médico ortopedista e da empresa que industrializa o biomaterial. Existem normas que determinam características dos implantes, desde a matéria prima, até o produto final. Respeitar estas normas constitui o ponto fundamental da questão.

Em 1964 a American Society for Testing and Materials (ASTM) cria o comitê F4, dedicado ao estudo e aperfeiçoamento de materiais e dispositivos para aplicações médicas.

Para padronização dos materiais para implantes é criada, em 1974 nos Estados Unidos a Society for Biomaterials, e ressalta a importância da criação de normas e procedimentos de padronização para esta categoria de materiais.

Em 1989 a International Organization for Standardization (ISO) propõe a Norma ISO 7206 que estabelece procedimentos para realização de testes em componentes femorais.

O congresso Norte Americano aprova a lei 94-295 que versa sobre dispositivos médicos, estabelecendo como autoridade de aplicação a United States Food and Drug Administration (USFDA).

No Brasil, o órgão responsável pela fiscalização deste tipo de produto é a ANVISA - Agência Nacional de Vigilância Sanitária, e tendo em vista a qualidade deficiente de implantes metálicos para osteossintese, através da Consulta Pública $\mathrm{n}^{0}$ 24 de 08/03/2002, publicada no D.O. de 11/03/2002, abre espaço para que sejam apresentadas propostas de especificações técnicas para implantes.

\subsection{A fadiga}

As preocupações com defeitos por fadiga tiveram início no século XIX. Em 1852, Wöhler promoveu experimentos aplicando cargas de forma cíclica, com 
tensões de flexão e torção. Os resultados formaram bases para montagem de um diagrama que foi o primeiro método lógico para prever o comportamento de componentes mecânicos sujeitos à fadiga (BARSOM, 1987).

Por ser a fadiga um processo que produz danos estruturais, a engenharia tem estudado exaustivamente o fenômeno, entretanto foi em 1960, com as experiências do engenheiro Paris, que teve início o desenvolvimento de testes específicos do interessante processo. Em suas experiências estudou a relação dos ciclos de carga com a propagação de trincas (PARIS et al., 1963).

\subsubsection{O processo de fadiga}

$\mathrm{O}$ processo de fadiga segue sempre um mesmo esquema. Inicialmente o material sofre um dano microestrutural a cada ciclo de aplicação da carga, geralmente em pontos de concentração de esforços. Este dano inicial leva à formação de uma pequena fenda que passa finalmente a propagar-se a uma velocidade que é função da fragilidade do material (VILADOT et al., 1989).

Segundo Martin et al., (1981), o processo de fadiga em material metálico ocorre segundo uma seqüência distinta de fases:

1. Nucleação da trinca. É caracterizado por um período de incubação que precede a nucleação da trinca propriamente dita. $\mathrm{O}$ aspecto característico é a formação de bandas de deslizamentos persistentes, ou seja, regiões do metal que sofrem deformações altamente localizadas. A trinca por fadiga inicia numa superfície livre, mas em raras oportunidades pode ter início no interior do material.

2. Propagação da trinca. A propagação de uma trinca ocorre ao longo dos planos cristalográficos das bandas deslizantes persistentes. Neste estágio, as trincas por fadiga são normalmente transgranulares, estendendo-se por dois a cinco tamanhos de grãos, não sendo possível a visão a olho nu. Quando a trinca passa a se propagar na direção normal à máxima tensão, temos o estágio de propagação da trinca. Microscopicamente verifica-se a presença de estrias, que é o resultado dos sucessivos avanços da trinca.

3. Ruptura final. Quando a superfície resistente remanescente não suporta 
mais a tensão aplicada, há a fratura brusca final.

Relata Colangelo (1969), que materiais em meio agressivo, como por exemplo no interior do corpo humano; podem apresentar comportamentos alterados, modificando o limite de fadiga. Levar em consideração as propriedades de fadiga é fundamental, particularmente em implantes ortopédicos, tendo em vista que estes tipos de dispositivos são utilizados em condições severas de solicitações e carregamentos, num meio hidro-eletrolítico.

\subsubsection{A fadiga em implantes metálicos}

Fadiga é o processo de alteração estrutural permanente, localizada e progressiva que ocorre em um material submetido a condições que produzem tensões e deformações flutuantes em alguns pontos e que podem culminar em trincar ou fratura completa após um certo número de ciclos.

Um dos fatores que contribui para a fratura ou soltura dos implantes ortopédicos é a fadiga do material utilizado (VIGORITA, 1999).

\subsection{Justificativa}

Há no mercado internacional um equipamento da empresa MTS $^{\circledR}$, denominado "858 Mini Bionix II Test System", que promove testes cíclicos em implantes de quadril, coluna e joelho. Em orçamento solicitado em novembro de 2001 (Anexo A), o sistema destinado somente ao teste de haste de prótese femoral foi orçado em 78.700 dólares, o que torna onerosa a realização de testes, e por conseqüência o desenvolvimento de materiais e modelos de implantes.

A nossa proposta é o projeto e desenvolvimento de uma máquina de movimentos cíclicos, para testes biomecânicos.

A máquina deverá ter um bom rendimento em termos de ciclos e cargas e ter uma faixa de abrangência suficiente para atender normas nacionais e internacionais. 


\subsection{Objetivo}

O objetivo deste trabalho foi o de desenvolver uma máquina de movimentos cíclicos capacitada a promover ensaios mecânicos nos diferentes biomateriais. 


\section{MATERIAL E MÉTODOS}

O projeto foi desenvolvido e executado no Laboratório de Bioengenharia da Faculdade de Medicina de Ribeirão Preto (USP), e na Oficina de Precisão da Universidade de São Paulo, Campus de Ribeirão Preto.

\subsection{Pré-protótipo}

A confecção do pré-protótipo teve como objetivo avaliar o mecanismo, a forma cíclica de transmissão de carga e a amplitude do movimento. Foram elaborados alguns modelos de dispositivos, porém a que nos pareceu apresentar as melhores características foi adotada. A Figura 1 apresenta do pré-protótipo da Máquina de Ensaio Cíclico.

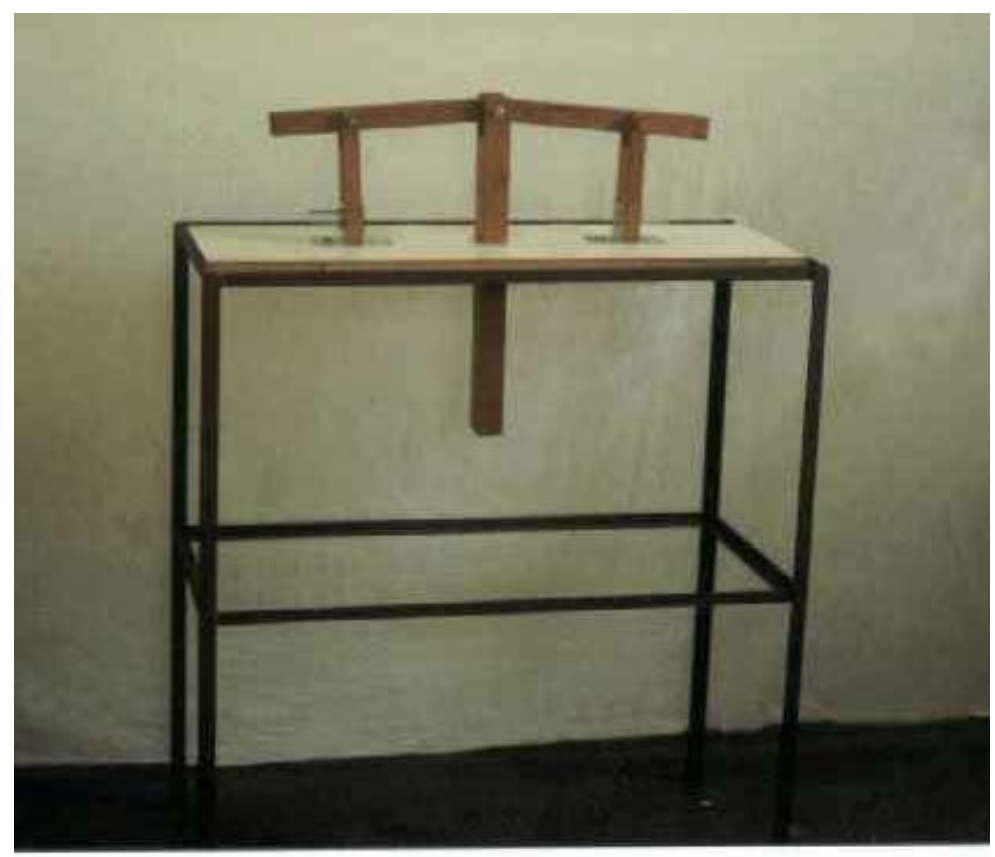

Figura 1. Foto do pré-protótipo 
As principais características que o pré-protótipo proporcionou e definiu foram:

- Modelo inicial;

- Utilização do processo de alavancas, o que permite variação da carga aplicada;

- Ensaio em dois componentes ao mesmo tempo;

\subsection{Protótipo Final}

\subsubsection{Estrutura da Máquina de Ensaio Cíclico - MEC}

A estrutura da máquina consiste de duas mesas, Figura 2 (a) e (b), com dimensões de 0,80 x 1,50 m, em chapas de aço 1020 com $1 \frac{1}{2}$ polegada de espessura.

Na mesa superior (a) estão os sistemas de alavancas, apoios e acessórios para fixação dos implantes para realização dos ensaios. Na mesa inferior (b) estão fixos os sistemas mecânicos (motor, acionamento, controle e refrigeração). A Figura 2 mostra a estrutura da máquina, antes do fechamento lateral.

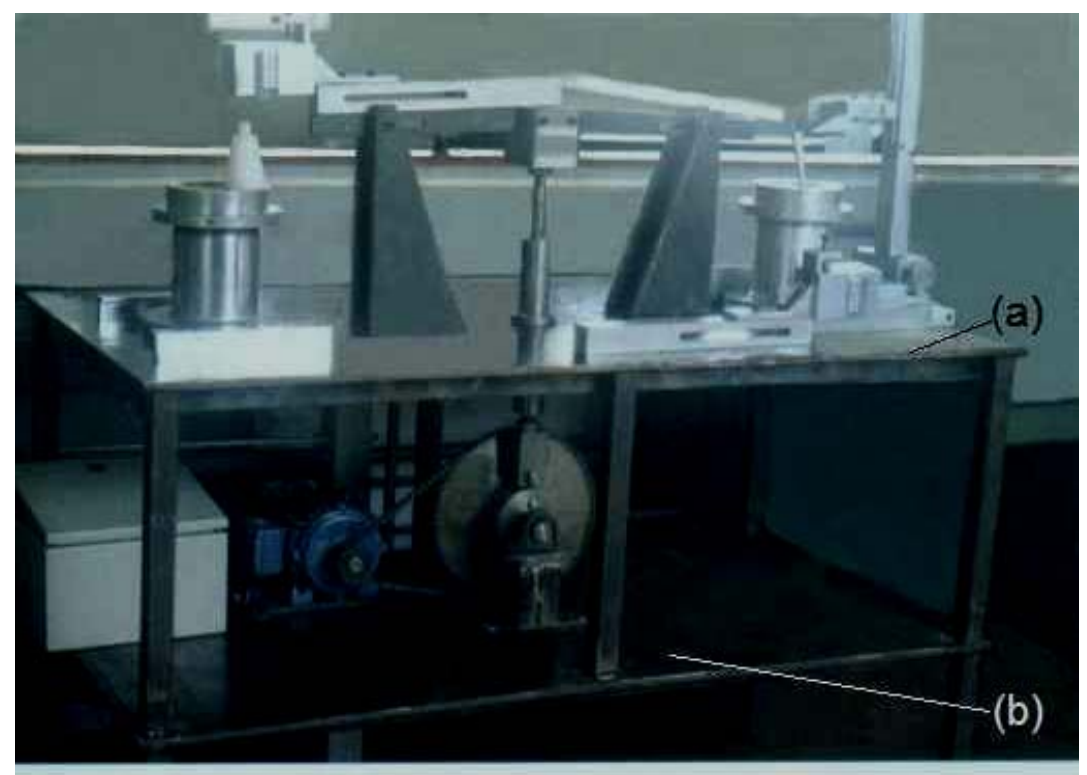

Figura 2. Estrutura da Máquina de Ensaio Cíclico.

(a) Mesa superior. (b) Mesa inferior. 
As duas mesas da máquina estão reforçadas com barras chatas de aço 1020 de 2 " x 3/8", soldadas na parte inferior da mesa. A Figura 3 mostra o reforço da mesa superior.

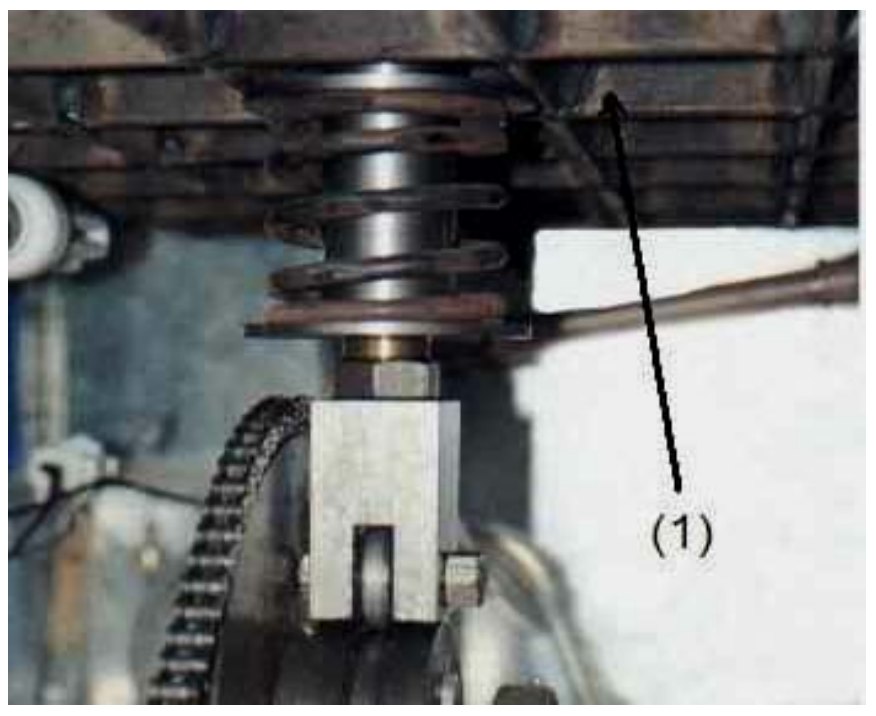

Figura 3. (1) Reforço da mesa superior.

Toda essa estrutura está fixada em quatro hastes de perfilado quadrado com 1 $1 / 2$ polegada, e após a instalação do motor, engrenagens, corrente e o excêntrico; foi fechada com chapas de aço galvanizado, constituindo assim a máquina de ensaio. $\mathrm{O}$ seu peso é de $650 \mathrm{Kg}$. A Figura 4 apresenta a Máquina de Ensaio Cíclico (MEC).

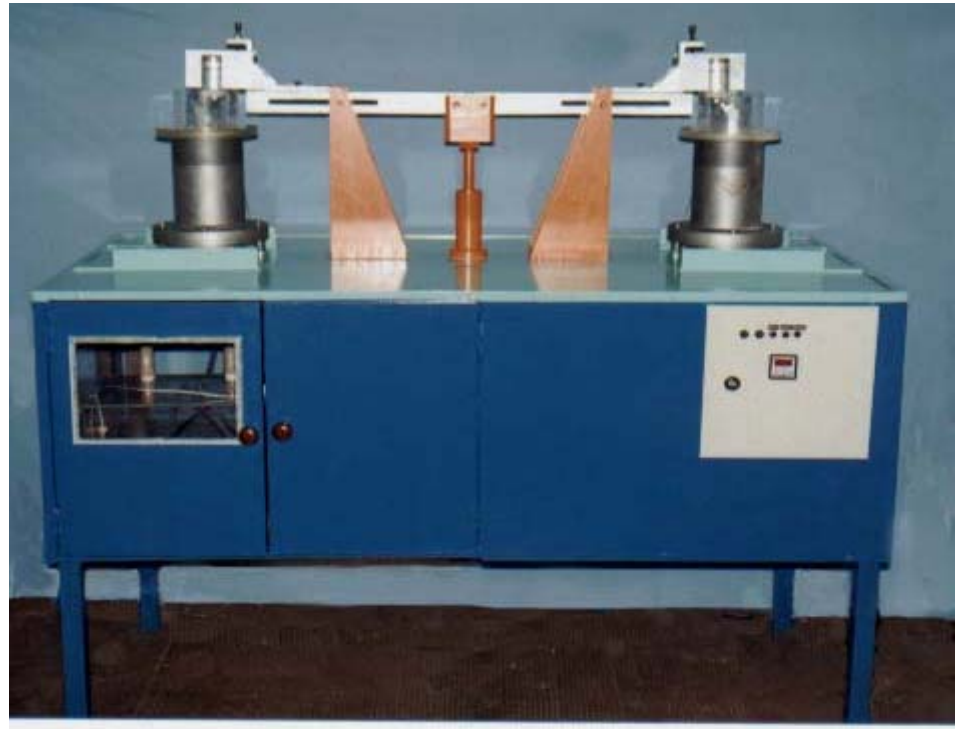

Figura 4. Máquina de Ensaio Cíclico - MEC 


\subsubsection{Sistema de acionamento do movimento}

Foi utilizado um motor trifásico, $2 \mathrm{HP}, 1800 \mathrm{rpm}$, da marca $\mathrm{WEG}^{\circledR}$, e o acionamento é pelo processo mecânico.

Conforme mostrado na Figura 5, o motor (1), por intermédio de uma corrente (2) faz girar uma engrenagem (3), adaptada a um eixo excêntrico (4), que aciona um pistão (5), que produz o movimento vertical das alavancas. Uma mola (6) apoiada na mesa superior promove o retorno do pistão, produzindo o movimento cíclico. A Figura 5 apresenta o sistema de movimentos cíclicos.

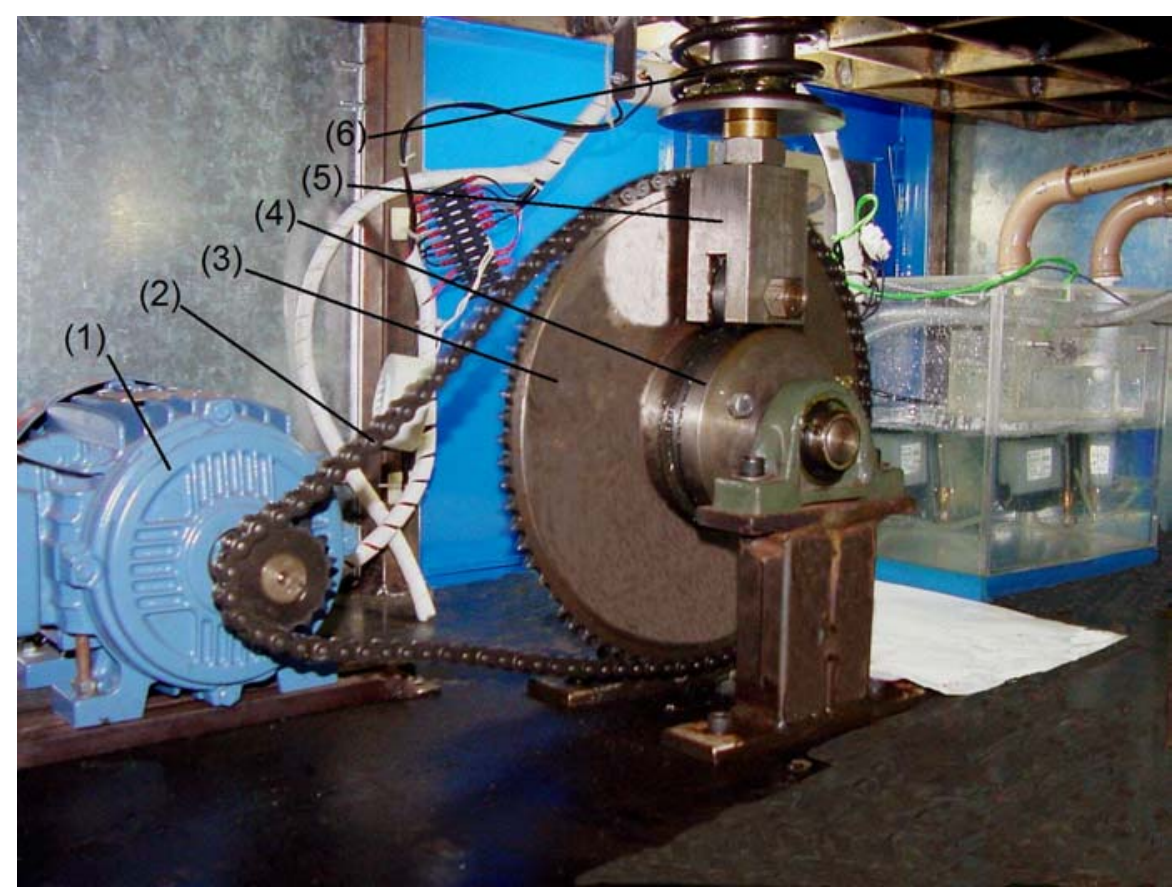

Figura 5. Mecanismo de movimentos cíclicos.

Há quatro buchas no pistão, e foram confeccionadas com poliamida (nylon ${ }^{\circledR}$ fundido), com lubrificante. É indicada para aplicações que envolvem deslizes, tendo alta resistência ao impacto e ao desgaste por atrito. 


\subsubsection{Sistema de transmissão de carga cíclica}

Como mostra a Figura 6, sobre a mesa superior estão fixas as duas bases (1) que suportarão as cargas e fará com que haja ampliação de cargas transmitidas pelos braços de alavanca (2) até os implantes.

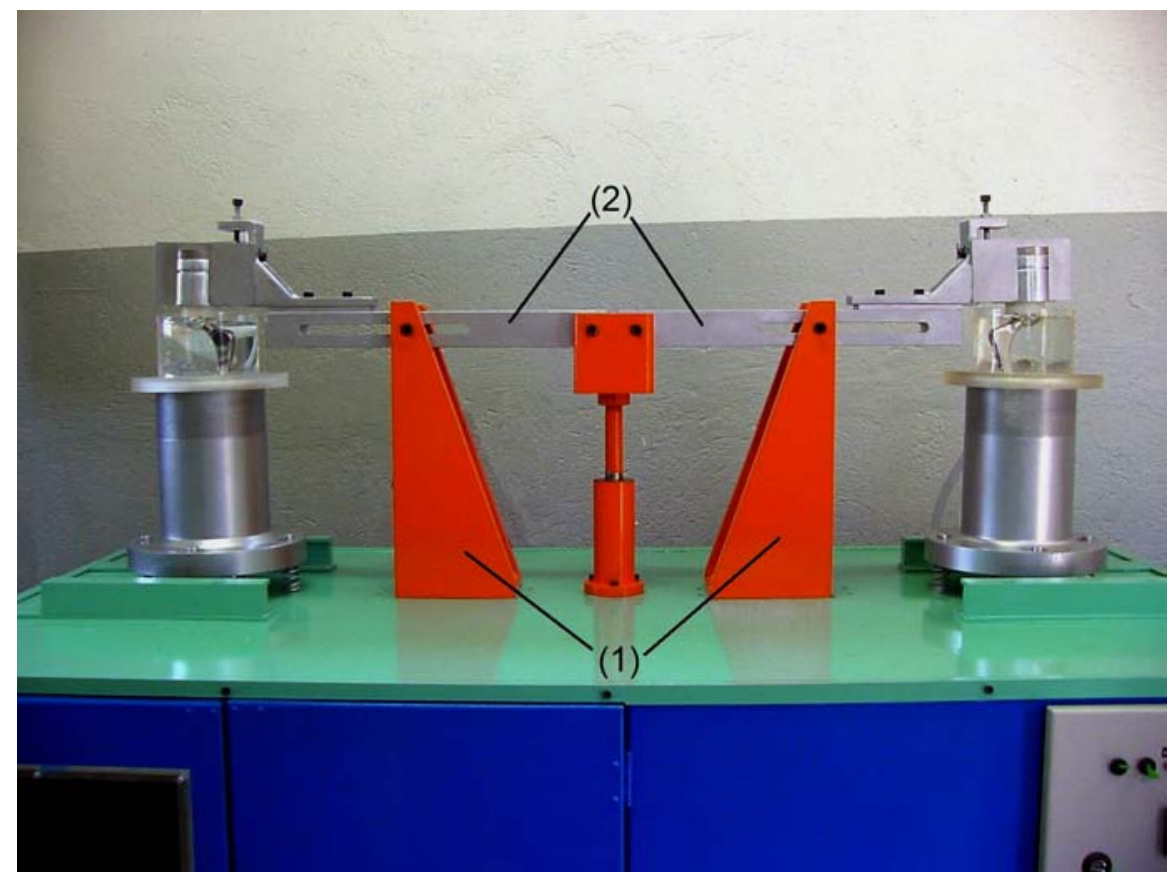

Figura 6. Parte superior da máquina.

(1) Bases. (2) Braços de alavancas.

\subsubsection{Dispositivo transmissor da carga}

A Norma ISO 7206/89, parte 4, relata que o mecanismo deverá ter baixa fricção, e para tanto foi desenvolvido um sistema de transmissão de carga por esferas Figura 7 (1), e um apoio Figura 7 (2) de polietileno, que é um polietileno de ultra alto peso molecular, que tem como característica a alta resistência; para transmitir a carga para o implante, simulando o acetábulo. 


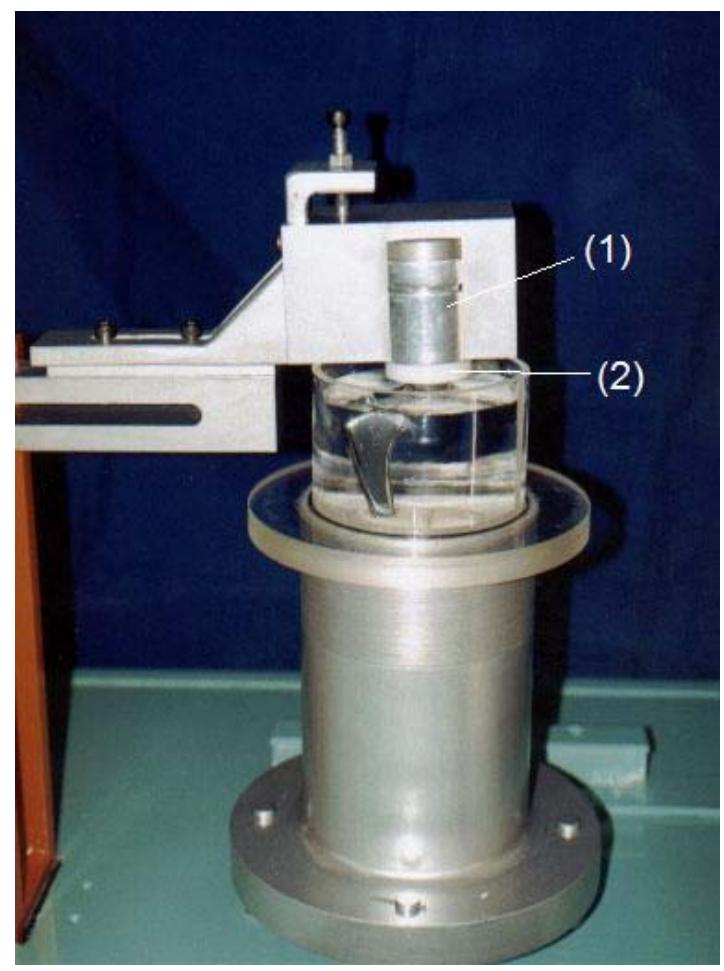

Figura 7. Mecanismo de transmissão de carga (1) Dispositivo de carga. (2) Apoio de polietileno.

As Figuras 8 e 9 mostram detalhes do sistema, permitindo visualizar o esquema de distribuição das esferas.

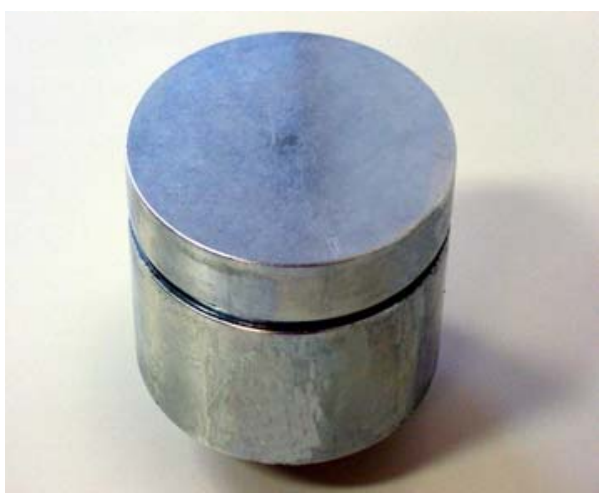

Figura 8. Dispositivo de transmissão de carga

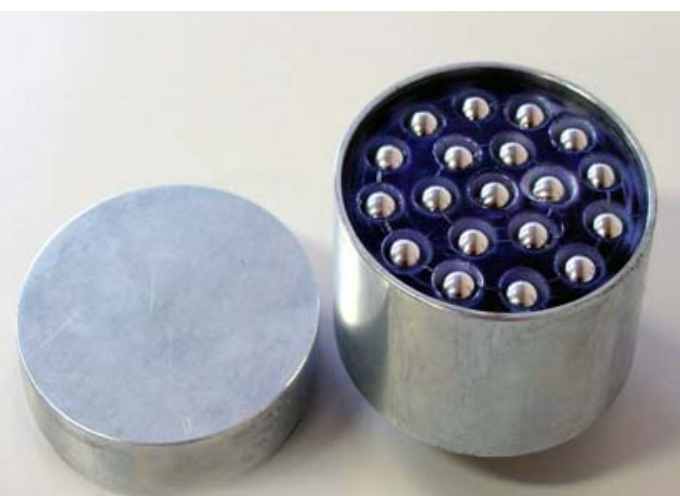

Figura 9. Dispositivo de transmissão de carga, mostrando as esferas. 


\subsubsection{Controle dos ciclos}

O controle do número de ciclos é feito por intermédio de um inversor de freqüência, da marca $\mathrm{WEG}^{\circledR}$.

A freqüência é do tipo PWM senoidal. Permite o acionamento a velocidade variável de motores de indução trifásicos padrão, com potência entre 0,25 e $2 \mathrm{CV}$.

Corrente nominal de saída varia de 1 a 7A. Alimentação a partir de redes monofásicas de 200-400 V e trifásicas de 0-240 V e 80-480 V.

A tensão da rede é transformada em tensão contínua através do conjunto retificador e banco de capacitores. Forma-se assim, o circuito intermediário, a partir do qual o estágio inversor de potência gera a alimentação trifásica para o motor com tensão e freqüências variáveis.

Utiliza um microcontrolador de 16 bits para gerenciar todo o sistema.

$\mathrm{O}$ inversor de freqüência possui um painel que permite monitorar todas as funções, como habilitar o inversor via rampa, inverter o sentido de rotação do motor, efetuar programações, bem como mostra a freqüência enviada ao motor. O painel está apresentado na Figura 10.

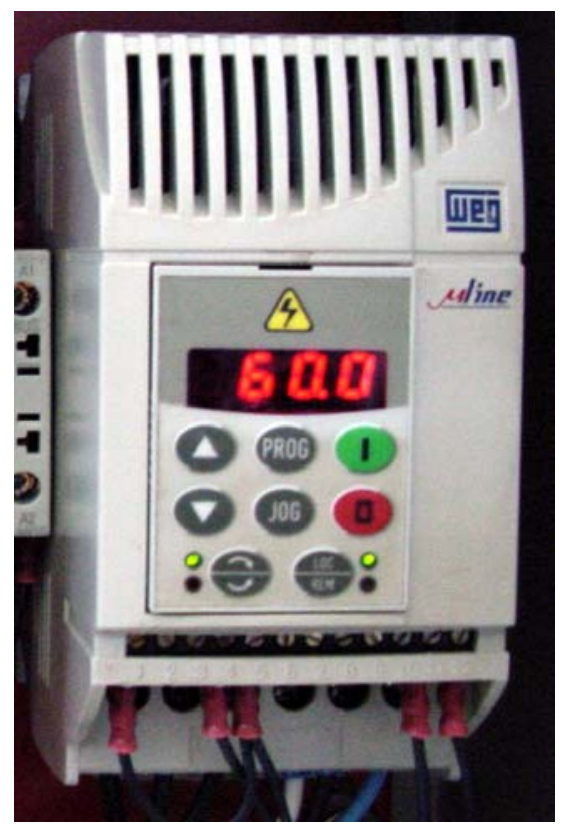

Figura 10. Painel do inversor de freqüência. 


\subsubsection{Sistema de temperatura e fluxo do líquido que envolve o implante}

Para promover a simulação dos líquidos corpóreos, nos componentes a serem ensaiados, foi instalado um reservatório em acrílico com as dimensões de 300x300x250mm, e colocados 13,5 litros de soro fisiológico ( $\mathrm{NaCl}$ ) com concentração de 9 g/l. A Figura 11 mostra o reservatório.

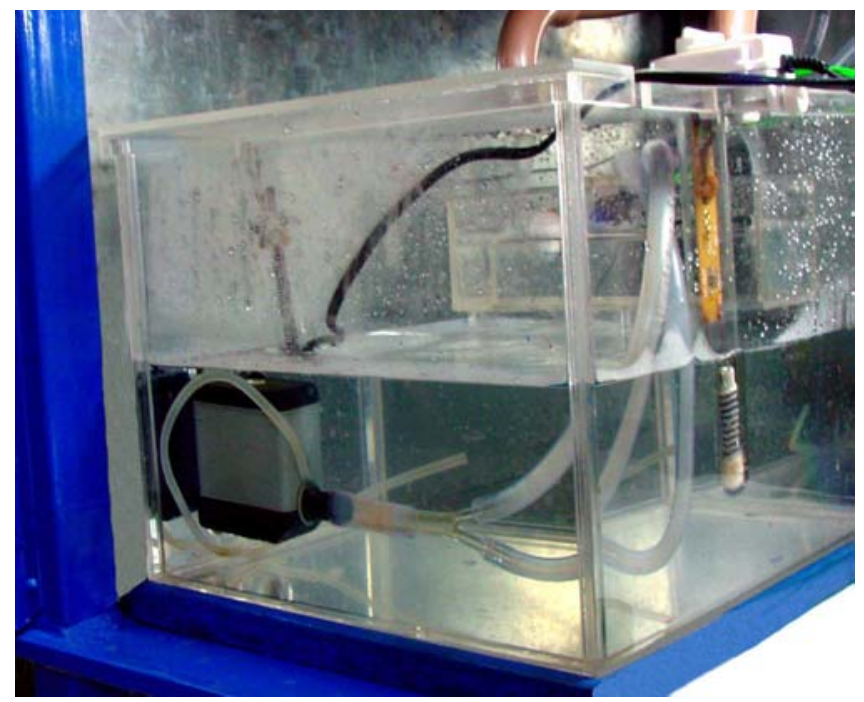

Figura 11. Reservatório de soro fisiológico

a) - Temperatura: O soro fisiológico deve estar a uma temperatura de $37^{\circ} \mathrm{C} \pm 1^{\circ} \mathrm{C}$, e para isso há um aquecedor, com um termostato da marca Heater Seven $\operatorname{Star}^{\circledR}$ - AC 110/120 8" $100 \mathrm{~W}$, que permite o controle da temperatura. O monitoramento da temperatura será feito por meio de um termostato digital, Marca Inova $^{\circledR}$, Mod. Inv-1701 - 220V, com alimentação e controle independentes, e um visor mostrando a temperatura do soro fisiológico. Caso haja algum problema e a temperatura saia da faixa de $36-38^{\circ} \mathrm{C}$, o motor será desligado automaticamente, e um alarme sonoro será acionado.

b) - Fluxo do soro fisiológico: Para promover a movimentação contínua do soro, foi instalada uma bomba hidráulica submersa, da marca $\operatorname{Atman}^{\circledR}$, Mod. AT010, Motor AC 110/60 Hz - 17W. Hmáx 1,60 m, e Qmáx 1200 litros/hora. O fluxo é monitorado por um MicroSwitch e uma bóia de isopor, colocados em uma pequena caixa, instalada dentro do reservatório de soro. Este pequeno reservatório recebe o 
retorno do soro que passa pelo implante a ser ensaiado. O implante é envolvido pelo soro fisiológico em um reservatório de acrílico que permite a visualização durante o teste. O soro entra o reservatório por uma mangueira de silicone, Figura 12 (1), e o retorno se faz por gravidade através de duas mangueiras, Figura 12 (2).

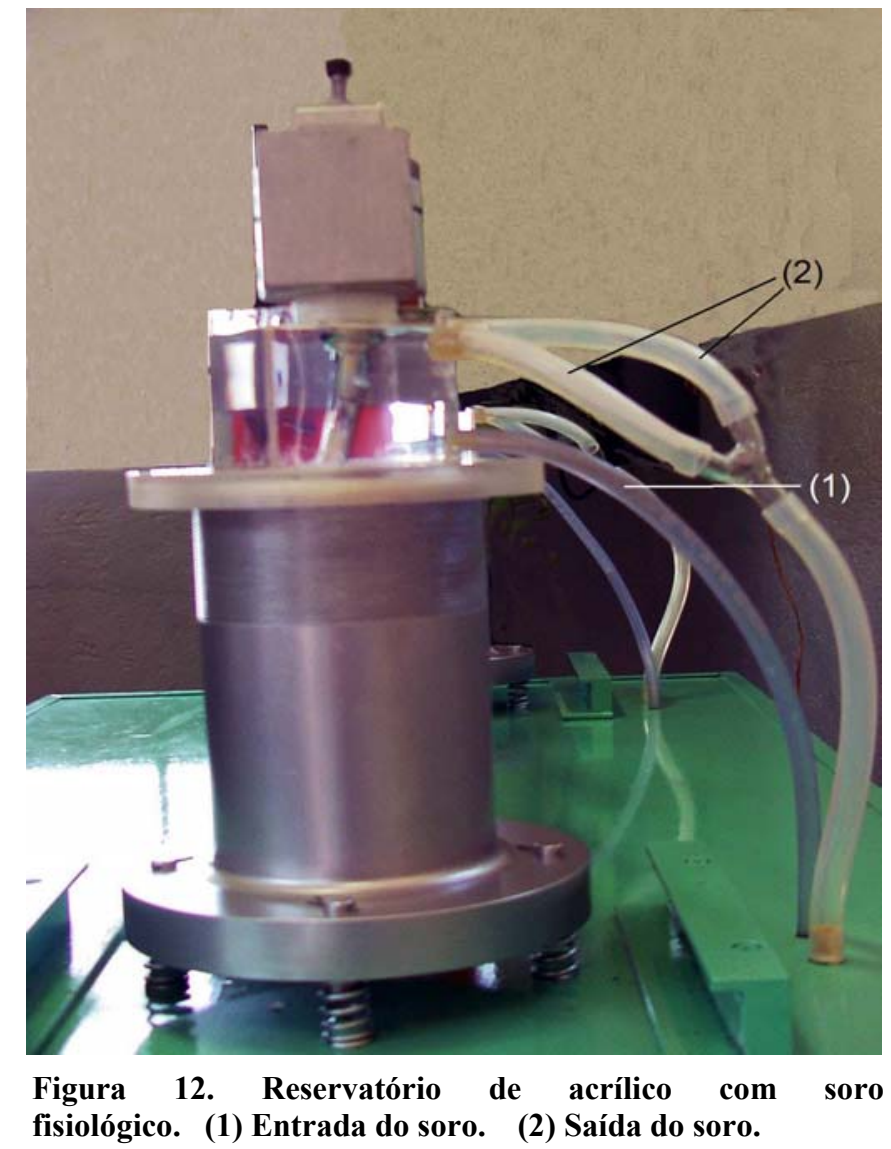

\subsubsection{Painel de controle e monitoramento}

Na parte frontal da máquina, do lado esquerdo há um visor em acrílico que permite, durante a realização do teste, visualizar o reservatório de soro fisiológico com todo sistema instalado, sem a necessidade de abrir o compartimento. O painel de controle está instalado do lado direito. Na parte externa do painel estão os comandos e indicações de funcionamento. A Figura 13 mostra a parte frontal da máquina, onde estão o visor de acrílico e o painel. 


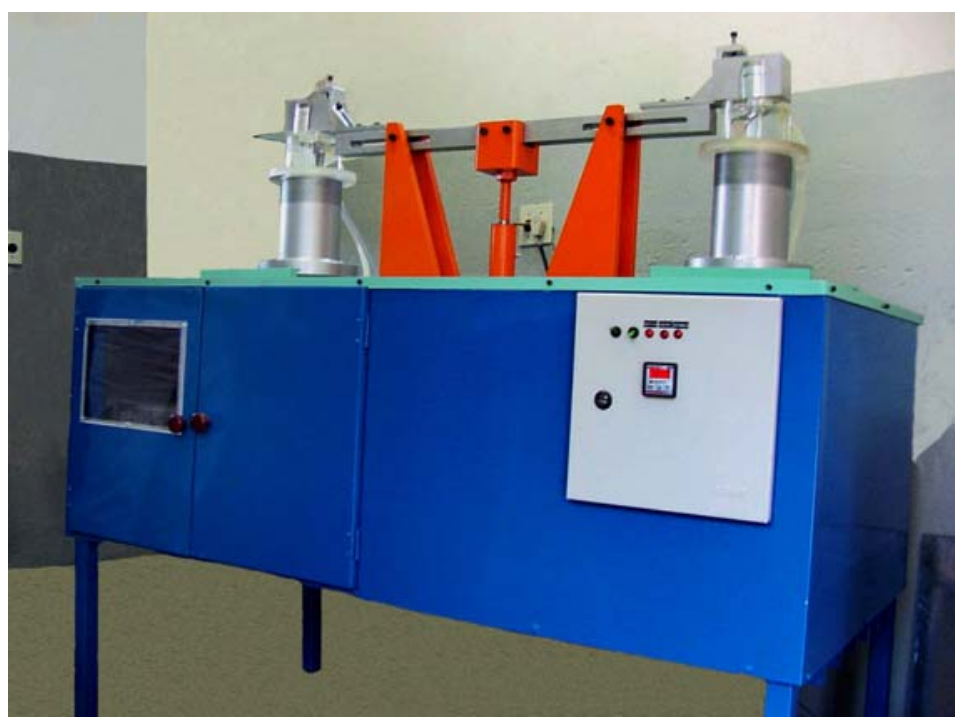

Figura 13. Parte frontal da máquina.

O painel externo, como mostra a Figura 14, possui as seguintes chaves e indicadores:

1) Interruptor que aciona uma lâmpada interna;

2) interruptor que aciona o motor;

3) lâmpada que indica o funcionamento do motor;

4) lâmpada que indica o funcionamento do aquecedor;

5) lâmpada que indica o funcionamento da bomba hidráulica;

6) visor do termostato digital, que indica a temperatura do soro fisiológico, e monitora a temperatura selecionada.

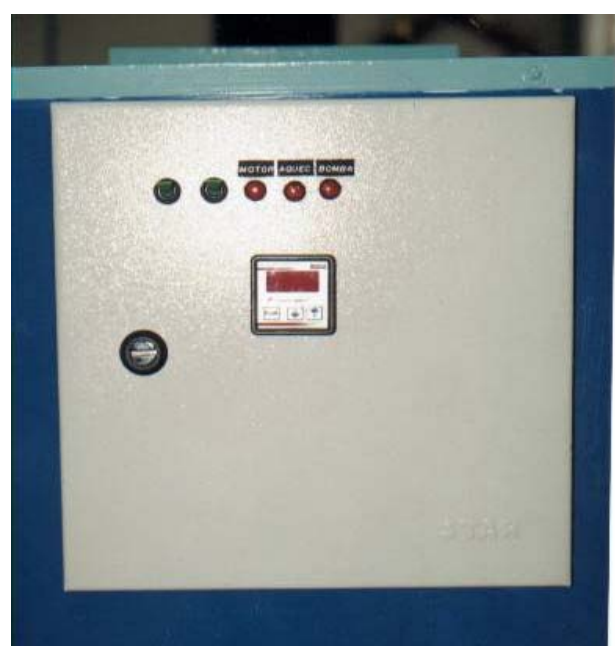

Figura 14. Painel externo de controle. 
$\mathrm{Na}$ parte interna do painel, como mostra a Figura 15, há os seguintes interruptores (disjuntores termoelétricos):

1) Chave geral;

2) acionamento da bomba hidráulica;

3) acionamento do aquecedor (termostato);

4) acionamento do motor.

5) contactor para controlar os sistemas de segurança do fluxo e da temperatura do soro fisiológico;

6) inversor de freqüência para controle dos ciclos do motor.

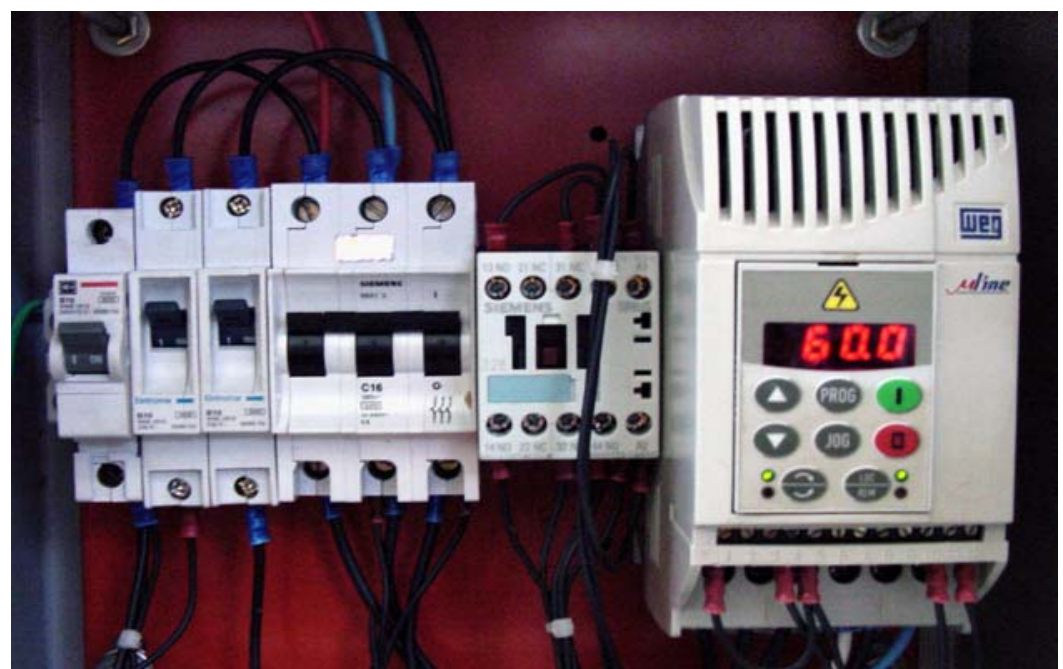

Figura 15. Parte interna do painel de controle. 


\section{VALIDAÇÃO DA MÁQUINA DE ENSAIO CÍCLICO}

Após o projeto e construção de uma máquina, principalmente destinada a ensaios cíclicos, deverá ser feita a sua validação, para comprovar a resistência de seus componentes e o funcionamento dos sistemas instalados.

Para essa validação adotamos um ensaio de fadiga, seguindo determinações das Normas ISO 7206 parte 4 (Determination of endurance properties of stemmed femoral components with application of torsion) e ASTM F 1612-95 (Standard Practice for Cyclic Fatigue Testing of Metallic Stemmed Hip Arthroplasty Femoral Components with Torsion).

\subsection{Ensaio de fadiga}

\subsubsection{Controle e calibração da carga aplicada}

A máquina permite a regulagem da carga aplicada com a mudança do apoio do braço de alavanca, Figura 16 (1) combinado com a tensão nas quatro molas, Figura 16 (2) colocadas sob o suporte de fixação da haste femoral. As molas foram industrializadas pela empresa Hidrau \& Spring ${ }^{\circledR}$, sendo cada uma com tensão de 200 $\mathrm{N}$ para uma variação de $2 \mathrm{~mm}$ no excêntrico. 


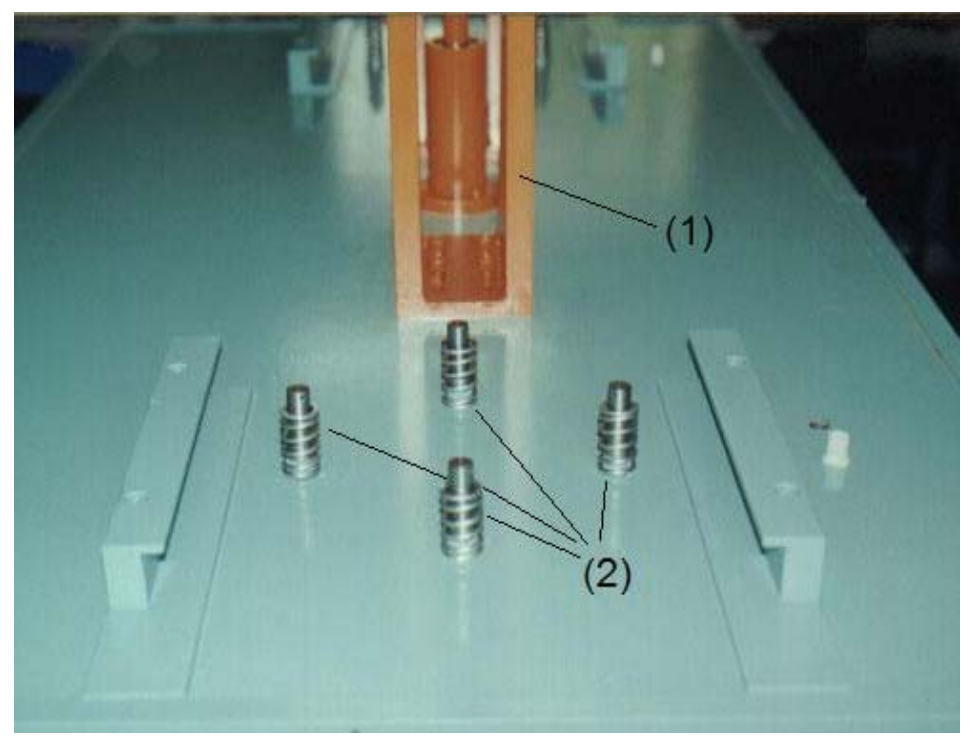

Figura 16. Sistema de controle da carga.

(1) Apoio do braço de alavanca. (2) Molas.

A carga aplicada nas peças e dispositivos a serem ensaiados é regularmente monitorada por uma célula de carga $\operatorname{Kratos}^{\circledR}$ ligada a uma ponte de extensometria $\left(\operatorname{Sodmex}^{\circledR}\right)$.

Este procedimento impede que o teste seja feito com cargas diferentes daquelas determinadas pela norma. Para o ensaio de haste de prótese femoral, a Norma ISO 7206/4 fixa uma faixa entre 200 e 300 N.

Antes de iniciar o teste propriamente dito, a carga a ser aplicada é calibrada com uma célula de carga, como mostra as Figuras 17.

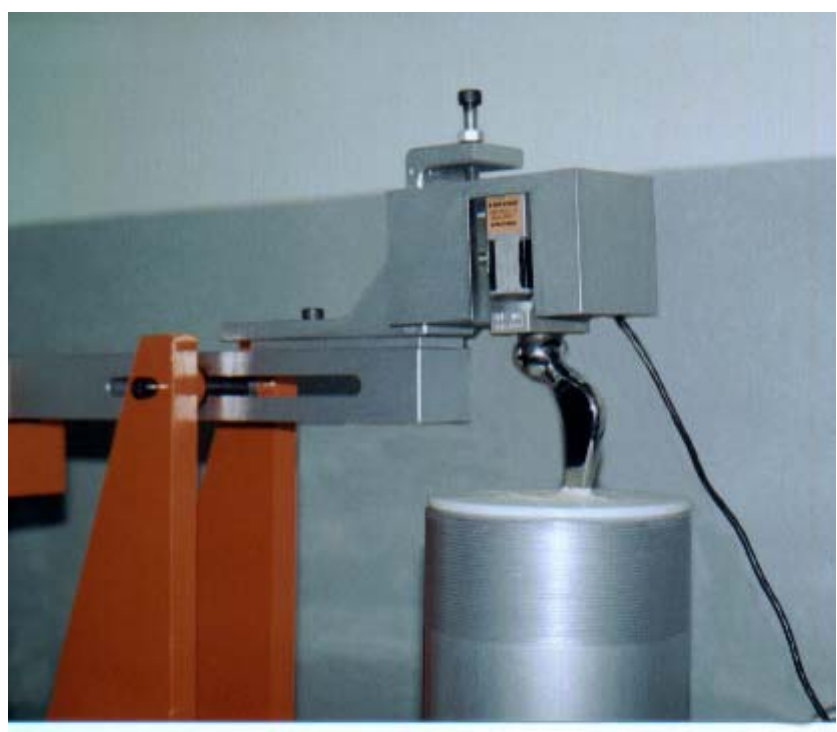

Figura 17. Calibração da carga 


\subsubsection{Recipiente para recepção da haste femoral}

Composto de um recipiente de aço pesando $32 \mathrm{~kg}$, e possui um orifício cônico. Para evitar o contato do soro físiológico com parte metálica do suporte, foi colocada uma peça de polietileno, com um orifício, destinado a receber o cimento e a haste da peça a ser ensaiada. A Figura 18 mostra o recipiente.

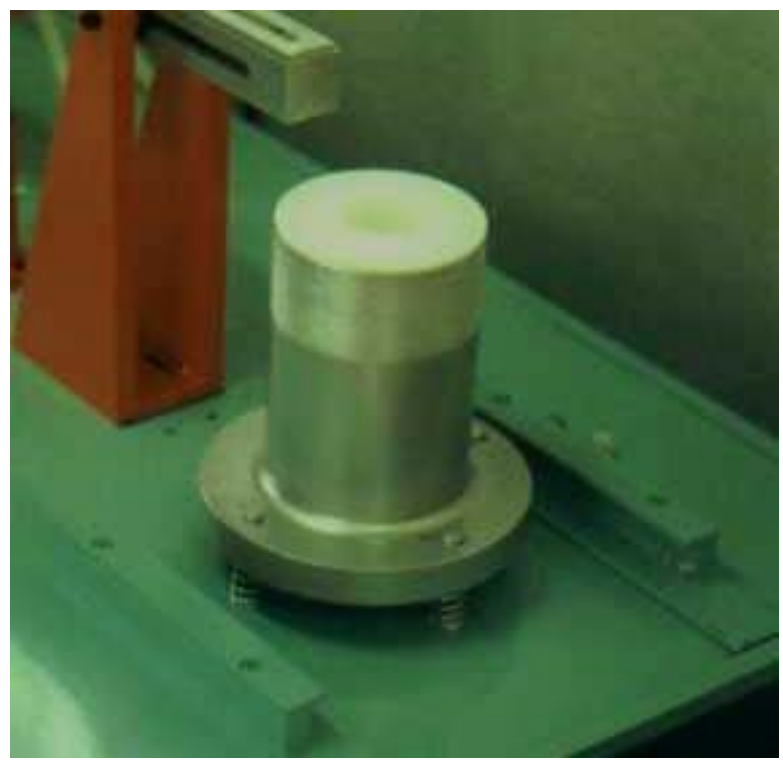

Figura 18. Recipiente para fixação da haste da prótese femoral.

\subsubsection{Fixação da haste femoral}

Relata a norma que a fixação da prótese femoral deverá ser feita em um meio de moldagem de não seja afetado pela solução salina, não deverá fraturar sob a aplicação da carga durante o teste, nem sofrer deformação excessiva ou "creep". Indica como satisfatório para a realização do teste a resina de moldagem epóxi, o cimento de alta alumina, ou o próprio cimento ósseo ortopédico. Optamos por utilizar o cimento ósseo ortopédico.

Este cimento não é adesivo. Ele desempenha sua função de apoio, porque envolve firmemente o componente a ser ensaiado. 


\subsubsection{Posição da haste femoral}

Relata a norma que para a realização do teste, a haste da prótese femoral deverá estar posicionada com as seguintes inclinações.

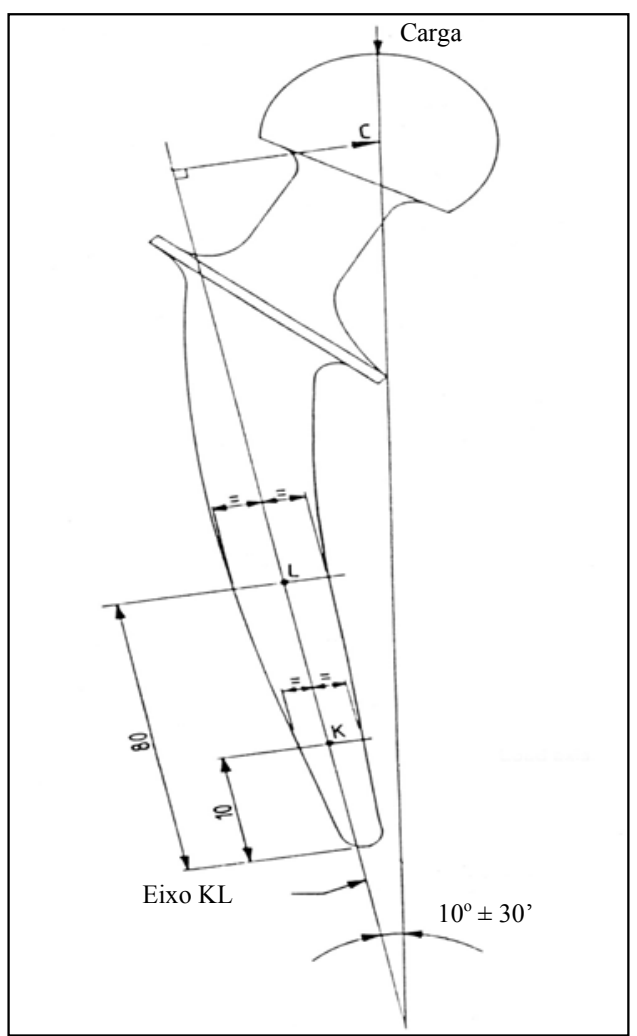

Figura 19. Inclinação da haste femoral (M-L) Fonte: Norma ISO 7206/4

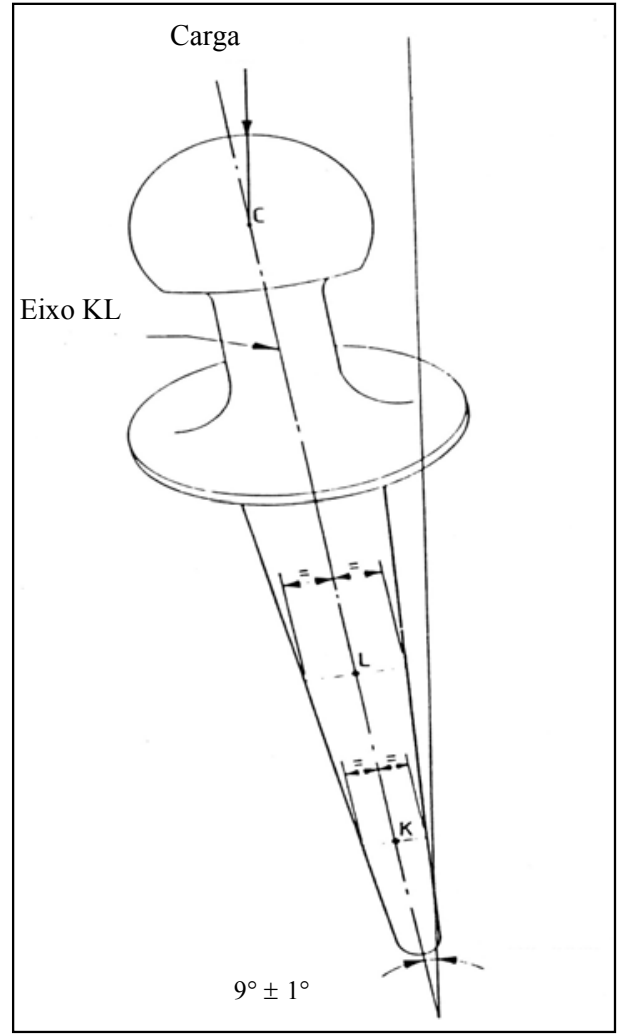

Figura 20. Inclinação da haste femoral (A-P) Fonte: Norma ISO 7206/4

\subsubsection{Gabarito posicionador}

Para a fixação da haste da prótese no recipiente, posicionada com as inclinações determinadas pela norma, foi desenvolvido um gabarito posicionador. A Figura 21 mostra este gabarito.

Diante das características e dimensões de cada tipo de haste femoral, o gabarito é adaptado para posicioná-la nas inclinações exigidas pelas normas. 


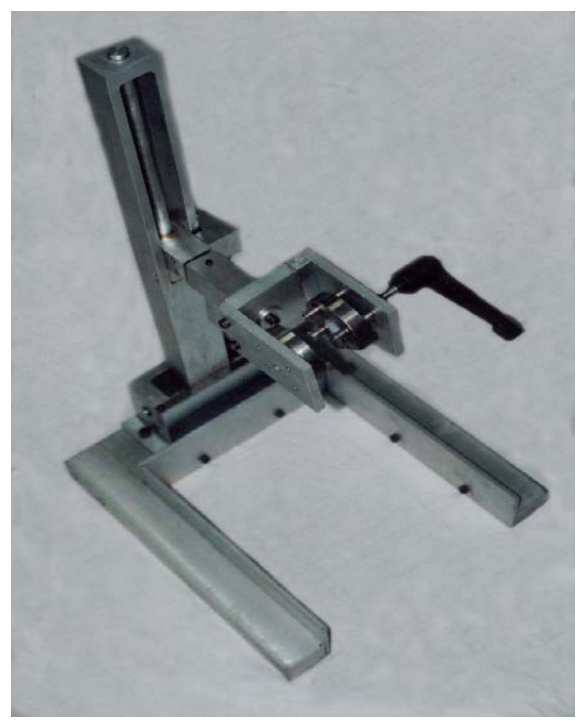

Figura 21. Gabarito posicionador da haste femoral

Para a determinação da inclinação da haste devemos proceder da seguinte forma:

Tendo em vista as diferentes formas e modelos de hastes, define-se o eixo $\mathrm{KL}$, formado pelos pontos K (fica a $10 \mathrm{~mm}$ da ponta da haste) e $\mathrm{L}$ (fica a $80 \mathrm{~mm}$ da ponta da haste).

O eixo KL deverá ficar inclinado $10^{\circ} \pm 30^{`}$ (M-L), com o eixo vertical da aplicação da carga, passando pelo Ponto C, que fica situado no centro de curvatura da cabeça femoral.

Da mesma forma, inclina-se o eixo KL $9^{\circ} \pm 1^{\circ}$ (A-P), em relação do eixo vertical, paralelo à aplicação da carga.

Após a fixação da haste no gabarito, por meio de um guia colocado na mesa da máquina de ensaio, ela é levada até a posição de ensaio, como mostra a Figura 22. O ajuste da posição ideal se dá, além da utilização do guia (1) que permite a mobilidade longitudinal, através do movimento do cursor (2), que permite a mobilidade transversal. O ajuste da altura é feito através da movimentação do mecanismo (3) que fixa a prótese femoral. Este movimento permite a mobilidade vertical. 


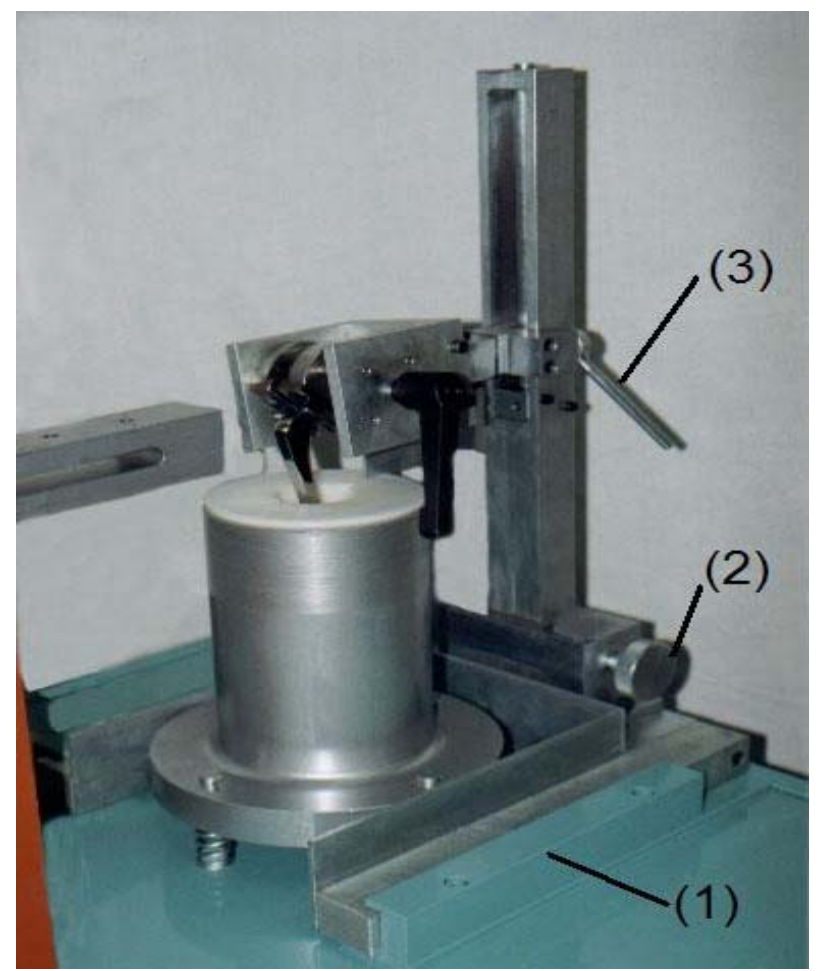

Figura 22. Posicionamento da haste femoral para o ensaio. (1) Guia; (2) Cursor; (3) Alavanca do mecanismo que fixa a haste femoral.

Relata a norma que o fracasso dos componentes femorais ocorre na maioria das vezes entre 25 e $90 \mathrm{~mm}$ abaixo da cabeça femoral, por isso há um sistema que mantém a prótese livre, sem fixação à distância de $80 \mathrm{~mm}$, medidos a partir do centro da cabeça femoral, conforme exige a norma.

Após o posicionamento, eleva-se a prótese femoral, coloca-se o cimento, em seguida abaixa-se a prótese, introduzindo a haste no cimento acrílico ortopédico, como mostra a Figura 23. 


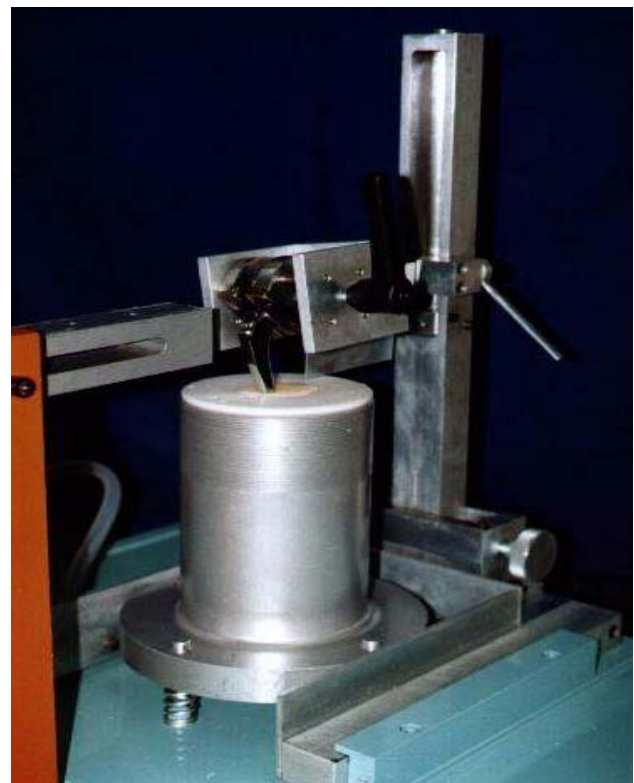

Figura 23. Fixação da haste femoral no cimento acrílico.

\subsubsection{Aplicação da carga}

Após a secagem do cimento, retira-se o gabarito e coloca-se o reservatório onde irá circular o soro fisiológico. Em seguida, adapta-se o mecanismo que irá promover a carga cíclica no componente femoral, como está sendo mostrado na Figura 24.

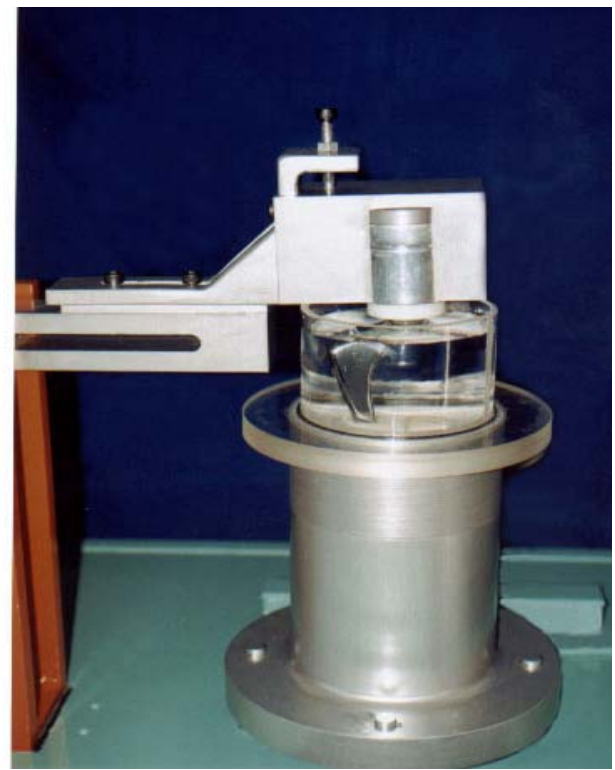

Figura 24. Mecanismo de carga apoiado na prótese femoral 
Segundo a norma, uma carga aceitável estará entre 200 e 300 N, e deverá ser cíclica.

A norma não especifica a variação de carga a ser aplicada, nem o número de ciclos de carga, mas indica como ideal uma freqüência de 1 a $10 \mathrm{~Hz}$, e a duração do teste em cinco milhões de ciclos $\left(5 \times 10^{6}\right.$ ciclos $)$. A freqüência de $1 \mathrm{~Hz}$ é indicada para componentes não metálicos e $10 \mathrm{~Hz}$ para componentes metálicos.

Desta forma a duração do teste, adotando-se $10 \mathrm{~Hz}$, ficaria em 139 horas; e adotando-se $5 \mathrm{~Hz}$, ficaria em 278 horas.

Após a fixação das duas hastes, houve uma espera para a secagem do cimento e o início dos testes de 76 horas e 34 minutos.

Relata a norma que o ensaio deverá ser finalizado, quando ocorrer um dos eventos abaixo:

a. Afrouxamento da haste;

b. fratura do componente femoral;

c. conclusão do número de ciclos previstos para o ensaio.

Durante o período de ensaio, foi preenchido um Relatório de Acompanhamento Diário (Anexo B).

Após a conclusão dos ensaios, deverá ser elaborado um relatório final contendo as informações do modelo a seguir:

\section{RELATÓRIO}

1. Referência normativa:

2. Identificação do componente femoral:

3. O meio de fixação (moldagem) da haste femoral:

4. Cargas utilizadas: Máxima:

Mínima:

5. Duração do teste, em ciclos:

6. Freqüência da carga aplicada:

7. Ângulo de inclinação, em graus:

8. Distância de compensação da cabeça femoral:

9. Declaração dos resultados: 
10. Motivo pelo qual o teste foi finalizado:

\subsection{Resultados do teste de fadiga}

Após a conclusão do ensaio, foram retirados os cones de polietileno com as duas hastes fixadas do cimento, como mostra a Figura 25.

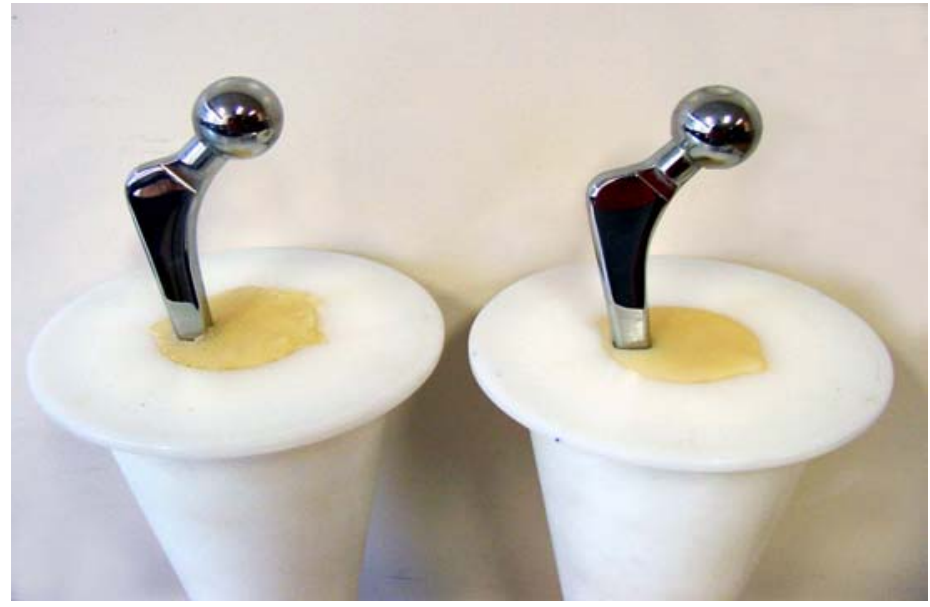

Figura 25. Hastes femorais e cimento, fixados no polietileno

Em seguida as hastes femorais, juntamente com o cimento, foram retiradas do cone de polietileno, o que está sendo mostrado na Figura 26. O conjunto estava fixo, indicando que não houve movimentação na interface cimento/polietileno.

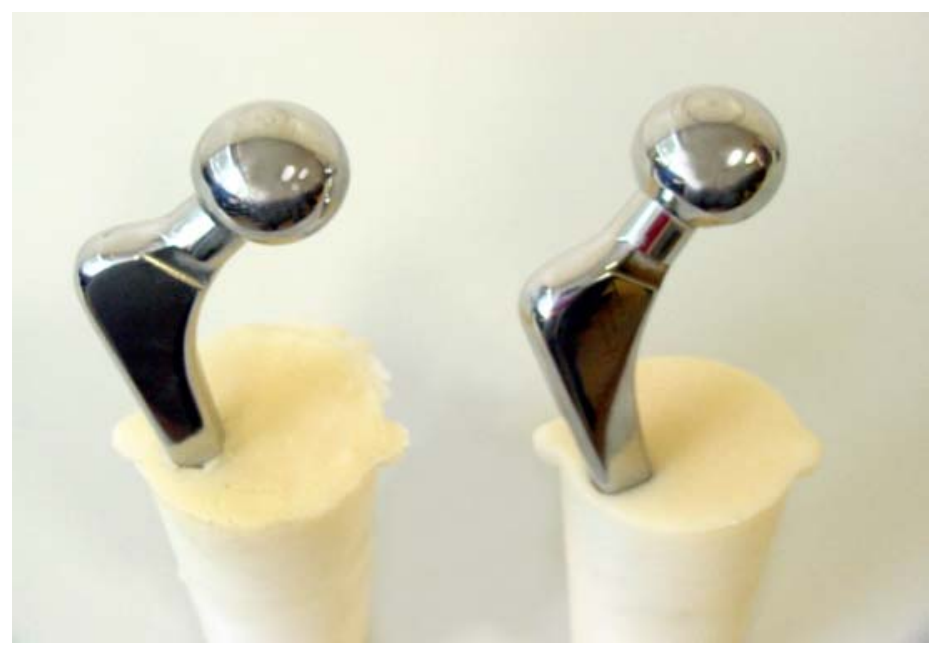

Figura 26. Hastes femorais fixadas no cimento acrílico 
Logo após as hastes foram removidas do cimento, e para isso foi necessário auxílio de um extrator, pois ambas estavam fixas no cimento, indicando que não houve soltura na interface prótese/cimento.

Os cones de cimento foram seccionados, com auxílio de uma serra manual e não foi observado algum tipo de trinca ou micro trincas do cimento, e as cavidades das hastes não mostraram deslizamento ou desgastes, como se observa na Figura 27.

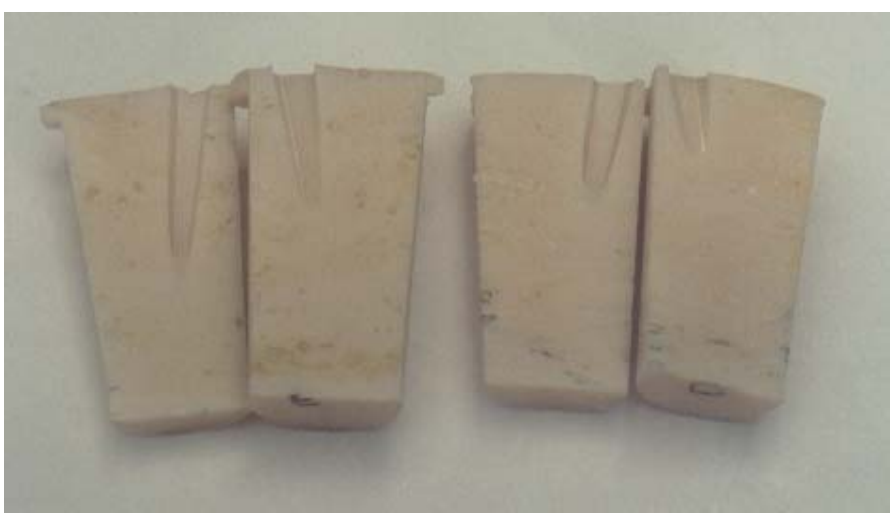

Figura 27. Cones de cimento acrílico seccionados.

Nas duas hastes femorais, foi feito um ensaio não-destrutivo, utilizando os métodos, procedimentos e materiais constantes da Norma ABNT NBR ISO 9583/1997 - (Implantes para cirurgia - Ensaio não-destrutivo - Inspeção por líquido penetrante de implantes cirúrgicos metálicos). 


\section{RESULTADOS}

Durante os testes iniciais a máquina ficou funcionando por mais de 30 horas, e estes testes foram feitos sem aplicação de carga. Nos testes das duas hastes femorais ficou em funcionamento durante 139 horas, com freqüência de $10 \mathrm{~Hz}$, totalizando mais de 6 milhões de ciclos, e com uma carga aplicada entre 200 e 300 $\mathrm{N}$. Durante todo esse período apresentou um funcionamento normal, destacando:

a. Não houve aquecimento anormal de nenhum componente da máquina;

b. Não houve falha, quebra ou substituição de peças da máquina durante todo seu funcionamento;

c. Não foram necessários ajustes da carga aplicada durante o ensaio realizado. 


\section{DISCUSSÃO}

Os materiais utilizados em implantes têm suas características determinadas por normas nacionais e internacionais, como por exemplo a Norma ASTM F 648-84 - (Standard Specification for Ultra-High-Molecular-Weight Polyethylene Powder and Fabricated Form for Surgical Implants), a Norma NBR ISO 7207 - Implantes para cirurgia, que em sua parte 1 refere-se a componentes femoral e tibial para próteses parcial e total de articulação de joelho - classificação e designação de dimensões; e em sua parte 2 refere-se a componentes para próteses parcial e total de articulação de joelho - superfícies de articulação feitas de materiais metálicos, cerâmicos e plásticos.

Relatam Muller (1983), Vigorita (1999), que algumas fraturas e solturas de implantes ortopédicos são motivadas por fadiga do material. Da mesma forma Apley (1996) descreve que forças de torção levam o implante ortopédico à fratura por fadiga.

A nossa proposta inicial foi desenvolver uma máquina de movimentos cíclicos para testes biomecânicos, uma vez que durante a marcha há uma grande solicitação em termos de cargas e ciclos.

O Laboratório de Bioengenharia da Faculdade de Medicina de Ribeirão Preto da Universidade de São Paulo não dispõe de equipamento para testes de fadiga em implantes ortopédicos, e um modelo da empresa MTS $^{\circledR}$ que faz somente o teste de próteses femorais teve seu custo orçado em 78.700 dólares (cotação de nov. 2001 Anexo A).

A falta de um equipamento que pudesse realizar ensaios cíclicos, associada ao custo de ensaios em equipamentos importados levou-nos ao desenvolvimento da máquina.

Nesta máquina foi adotado o sistema mecânico de transmissão de cargas, pela sua simplicidade em relação ao sistema hidráulico. Embora o sistema mecânico seja 
mais simples, a máquina apresentou eficiência e bom desempenho no ensaio realizado, condição esta relatada por Souza, (1979).

Durante o planejamento inicial, surgiu a necessidade da construção de um pré-protótipo para definir a forma de transmissão de carga aos componentes a serem ensaiados.

A elaboração do pré-protótipo foi importante para definir alguns sistemas, como a necessidade de um pistão para o movimento cíclico e também uma alavanca para a transmissão de carga.

A vantagem do sistema de alavanca é a variação na amplitude de movimento pela simples mudança do apoio, e principalmente em se conseguir cargas mais elevadas, sem exigir esforço adicional do motor; somente pelo controle na distância do braço de alavanca.

Os ensaios de fadiga são de longa duração, e para acelerar o processo foram adaptadas duas alavancas, permitindo assim o teste de dois componentes ao mesmo tempo.

Para definir a amplitude de movimento inicial foi projetado um eixo excêntrico que transmite o movimento para o pistão. A amplitude de movimento na transmissão de carga é dada pela combinação da mudança de apoio das alavancas com a amplitude do excêntrico.

Para a elaboração do protótipo final, surgiram dificuldades no início da construção por se tratar de uma máquina sem similar no mercado quanto ao mecanismo de transmissão; e a carência de mão de obra especializada para a parte mecânica e eletro-eletrônica.

Uma das preocupações foi quanto ao dimensionamento das mesas, uma vez que recebem além do sistema de acionamento, o sistema de transmissão de cargas e os acessórios para fixação dos componentes a serem ensaiados.

Foram instaladas duas chapas de aço, de $0,80 \mathrm{~m}$ por $1,50 \mathrm{~m}$, porém devido a estas dimensões, nos testes iniciais envolvendo cargas, houve um pequeno deslocamento vertical das mesas e foi necessário soldar um reforço com barras chatas de aço em de perfil, formando uma treliças, na parte inferior das duas mesas. Este procedimento aumentou a rigidez do sistema, não permitindo a perda de carga realizada pela flambagem das mesas. 
$\mathrm{Na}$ máquina foram utilizados dois sistemas de molas, o primeiro consiste em uma mola envolvendo o pistão, fixada na parte inferior da mesa superior, que promove o retorno do pistão impulsionado pelo excêntrico em movimento, produzindo assim o movimento cíclico. O outro sistema permite o controle e calibração da carga aplicada de acordo com as determinações das normas. Consiste de quatro molas colocadas sob o suporte de fixação do componente a ser ensaiado. A tensão das molas promove o contato contínuo do mecanismo de carga com o componente a ser ensaiado, evitando o impacto do carregamento cíclico.

Como previsto no pré-protótipo, o sistema de alavancas permitiu ampliar a carga aplicada nos componentes, sem sobrecarregar o motor, pela simples mudança nos apoios dos braços das alavancas.

Nas extremidades das alavancas foi adaptado o mecanismo transmissor de carga. Há um sistema de regulagem que permite adequar o teste para hastes com outras dimensões.

A opção pelo sistema de transmissão de movimentos do motor para o eixo excêntrico foi por corrente, que permite o controle efetivo dos ciclos do motor e a freqüência de carga e melhora o torque, uma vez que não permite deslizamentos na transmissão de movimentos para o sistema de carga. Uma desvantagem do uso da corrente é o ruído, e uma sugestão para minimizar seria a substituição por um sistema de correia dentada.

A potência do motor elétrico instalado na máquina de ensaio é suficiente para promover as cargas e ciclos exigidos pelas normas, e também assegura que o equipamento seja utilizado para cargas maiores, sem prejuízo do rendimento.

Em alguns testes biomecânicos, como por exemplo o realizado neste trabalho, as normas recomendam o uso de um sistema com soro fisiológico em constante movimento e refrigeração. Para isso foi instalado um reservatório em acrílico com um sistema de bomba hidráulica submersa e um termostato para manter o soro fisiológico em movimento e com temperatura controlada. Um sistema de segurança para o fluxo do soro fisiológico composto de uma chave bóia, e um termostato digital para a temperatura, evita que o funcionamento da máquina de ensaio seja monitorado constantemente, pois caso ocorra interrupção do fluxo do soro, ou a temperatura saia da faixa de $36-38^{\circ} \mathrm{C}$, o motor é automaticamente desligado e um alarme sonoro é 
acionado.

A máquina de ensaio cíclico possui um inversor de freqüência, que além de monitorar e controlar os ciclos exigidos no teste, altera a rotação do motor sem perda do torque. Esta condição permite adequação aos ensaios que exijam outras freqüências.

Todo equipamento após a sua confecção, mesmo que se tenha seguido todos os parâmetros e critérios durante a sua construção e montagem, é necessário que se faça sua validação. Essa validação consiste em testes preliminares que avaliem a resistência dos componentes da máquina e o funcionamento dos sistemas instalados (SCHROCK,1979).

A máquina de ensaio cíclico inicialmente passou por testes preliminares, onde ficou em funcionamento por mais de 30 horas, sendo verificados o sistema de transmissão, corrente, engrenagem, pistão, alavancas e a movimentação do soro fisiológico na temperatura exigida pela norma.

Em uma segunda fase foram realizados dois ensaios simultâneos em próteses femorais, seguindo determinações das normas ISO e ASTM.

As normas recomendam que seja aplicada uma carga entre 200 e $300 \mathrm{~N}$, durante 5 milhões de ciclos, e por isso durante as 139 horas de duração do teste foram realizadas medições da carga a cada 8 horas, com anotações em um relatório diário de acompanhamento do teste (Anexo B).

Analisando as anotações realizadas durante o ensaio, quanto à calibragem da carga, ciclos e freqüência, sistema de soro fisiológico, observou-se que a máquina atende as normas e o seu funcionamento mostrou-se eficaz. Essa eficiência foi verificada e anotada no relatório final das condições físicas da máquina, elaborado no final de cada teste.

Um ensaio que exija 5 milhões de ciclos, embora com pequenas cargas, pode fadigar componentes do equipamento de teste, e por isso recomenda-se que a cada 100 horas de funcionamento, sejam verificadas as condições de alguns componentes da máquina, como a fixação do motor, tensão da corrente de transmissão, dentes das engrenagens, rolamento do pistão que fica em contato com o excêntrico, ajuste do pistão (folga), fixação das alavancas e a fixação dos apoios das alavancas.

Independente desta manutenção periódica, caso ocorra variação da carga 
aplicada durante a realização do teste, deve-se verificar além dos componentes acima citados, a tensão das molas sob o suporte de fixação dos componentes, bem como da mola que promove o retorno do pistão.

$\mathrm{O}$ custo da máquina de ensaio cíclico ficou em torno de $\mathrm{R} \$ 12.000,00$.

Embora não seja objetivo principal deste trabalho discutir os resultados do ensaio de prótese femoral, como análise do cimento acrílico, componente acetabular, ensaio de líquido penetrante, é de grande relevância que pudéssemos registrar a avaliação final de um ensaio normatizado, utilizado para validar a máquina de ensaio cíclico, objetivo principal deste trabalho, e que envolveu biomateriais. Devido a isso alguns aspectos importantes podemos comentar: Nas duas hastes femorais ensaiadas não foram observadas trincas ou fissuras, com isso foram aprovadas no controle de qualidade onde se utiliza o ensaio cíclico de fadiga, como recomendam as normas.

Quanto à espessura do cimento ao redor da haste femoral Ramaniraka et al., (2000) em seus estudos sugerem que a espessura ideal está entre 3 e $5 \mathrm{~mm}$. Abaixo de $2 \mathrm{~mm}$ pode causar fratura no cimento, e acima de $7 \mathrm{~mm}$ aumentou o deslizamento na interface cimento-osso. Para o nosso trabalho, a exigência das normas era apenas para a não fratura do cimento, e preocupamos somente com a espessura mínima, e a fixação da haste no final do teste apresentava-se estável, sem deslizamento, e o cimento sem fratura. Para a preparação do cimento e a fixação da haste foram seguidas as determinações das normas ASTM F 451-86 e ISO 5833.

Vários autores (APLEY et al., 1996; SHROTRIYA et al., 2002; TEOH, 2002; NIINOMI, 2002; ALBRECHT et al., 2002) relatam testes de fadiga, porém os resultados referem-se somente ao material utilizado, e não ao produto manufaturado.

A ANVISA, Agência Nacional de Vigilância Sanitária, em Carta Consulta publicada no Diário Oficial de 11.03.2002 ressalta que a qualidade deficiente dos implantes resulta na necessidade de realização de freqüentes cirurgias ortopédicas desnecessárias, ocasionando traumas aos pacientes e maiores custos ao sistema de saúde. Diante disso abre espaço para que sejam apresentadas críticas e sugestões técnicas sobre implantes metálicos para osteossíntese, e ressalta a necessidade de certificação.

Com esta máquina em funcionamento, novas pesquisas que envolvam outros tipos de implantes e de materiais podem ser realizadas, com pequenas adaptações de 
acessórios de apoio e fixação dos componentes a serem ensaiados. Portanto, o Departamento de Biomecânica, Medicina e Reabilitação do Aparelho Locomotor da Faculdade de Medicina de Ribeirão Preto, da Universidade de São Paulo, tem à sua disposição uma máquina passível de ser qualificada para a realização de testes cíclicos de fadiga com qualidade e eficiência, atendendo as exigências das normas vigentes. 


\section{CONCLUSÃO}

O desenvolvimento de uma máquina de movimentos cíclicos para testes biomecânicos utilizando o sistema mecânico de transmissão de carga, com tecnologia nacional, é viável. 
7. ANEXOS 
ANEXOA

ORÇAMENTO DA MTS

\author{
MTS Quotation for \\ MTS Model 858 Bionix Femoral Stem Fatigue Test \\ System \\ Table of Contents \\ MTS Model 858 Mini Bionix Test System for single axis testing ..................... 2 \\ Options for MTS Model 858 Mini Bioni Test Syste $m$ for single axis testing ...5 \\ Standard Project Engineering and Services.......................................................5

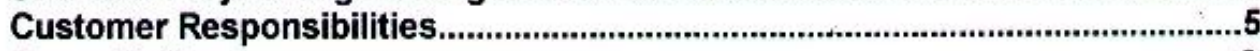

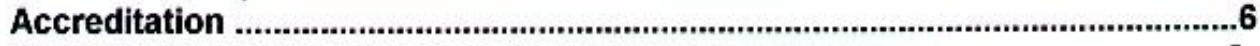

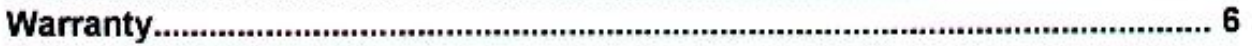 \\ Quotation Number: Budgetary \\ Quotation Date: 27-Sep-2001 \\ Valid Until: 26-Nov-2001 \\ Customer: Faculdade de Medicina de Ribeirăo Preto \\ Customer Contact: Sr. Carlos Alberto Marinheiro \\ Inquiry Number: \\ MTS Contact: Steve Trout \\ 952-937-4000 (Phone) \\ 952-937-4515 (Fax) \\ Steve.Trout@mts.com \\ Shipment Schedule: 120 Days, ARO \\ Shipment Terms: CIP Carriage,ins,paid (fr.pp) Destination \\ (per Incoterms, 2000) \\ Payment Terms: $40 \%$ on order, $60 \%$ on shipment, Net 30 days \\ Equipment Packe $d$ For: Ocean Freight
}

\title{
1.8 608.10 Uniaxial Hip Stem Fatigue Fixture
}

1

Model 608.10 Hip Stem Fatigue Fixture

- meets ASTM F 1440 and ISO 7206-3 Part 3 specifications.

- $5 \mathrm{kN}$ Axial force capacity

- Transparent chamber

- Specimen potting cup

- Bearing assembly

Note - Customer to supply potting medium and saline environment

TOTAL BASE PRICE 


\section{ANEXO B \\ RELATÓRIO DIÁRIO DE ACOMPANHAMENTO DO TESTE DE MOVIMENTOS CÍCLICOS}

\begin{tabular}{|c|c|c|c|c|c|c|c|c|c|}
\hline & & \multicolumn{6}{|c|}{ Relatório diário de acompanhamento } & & \multirow[b]{2}{*}{ Folha $\mathrm{n}^{\circ}$} \\
\hline & & & & & & & & & \\
\hline & & & \multicolumn{2}{|c|}{ Responsável: } & & & & & Dia: \\
\hline & & & & & & & & & \multirow{2}{*}{\begin{tabular}{|l|} 
Mês: \\
Ano:
\end{tabular}} \\
\hline & & & \multicolumn{2}{|l|}{ Material: } & & & & & \\
\hline \multirow{2}{*}{\begin{tabular}{ll|} 
Início & \\
\end{tabular}} & TTérmind & & \multicolumn{2}{|c|}{ TEMPO } & Frequêncial & \multicolumn{2}{|c|}{ Número de ciclos } & \multirow{2}{*}{ Observações: } & \\
\hline & & Horas & Minutos & Segundos & $(\mathrm{Hz})$ & parcial & TOTAL & & \\
\hline & & & & & & & & & \\
\hline & & & & & & & & & \\
\hline & & & & & & & & & \\
\hline & & & & & & & & & \\
\hline & & & & & & & & & \\
\hline & & & & & & & & & \\
\hline & & & & & & & & & \\
\hline & & & & & & & & & \\
\hline & & & & & & & & & \\
\hline & & & & & & & & & \\
\hline & & & & & & & & & \\
\hline & & & & & & & & & \\
\hline & & & & & & & & & \\
\hline & & & & & & & & & \\
\hline & & & & & & & & & \\
\hline & & & & Transport & te da follha $\mathrm{n}^{\circ}$ & & & & \\
\hline & & & & A transpo & & & & Visto: & \\
\hline & & & & & & & & & \\
\hline & & & & & & & & & \\
\hline
\end{tabular}




\section{REFERÊNCIAS BIBLIOGRÁFICAS}

ALBRECHT, J.; LUTJERING, G.; NICOLAI, H. P.; LIESNER, C. Improving the fatigue resistance of precision cast titanium orthopedic implants. Int. J. Fatigue, vol. 34, 2002, p. 2085-2092.

AMERICAN SOCIETY FOR TESTING AND MATERIALS, New York. F 451 86; Standard Specifications for Acrylic Bone Cement. New York, p. 97-103, 1986.

AMERICAN SOCIETY FOR TESTING AND MATERIALS, Philadelphia. F 1612 - 95; Standard Practice for Cyclic Fatigue Testing of Metallic Stemmed Hip Asthroplasty Femoral Components With Torsion. Philadelphia, 1995.

APLEY, A. G.; SOLOMON, L. Ortopedia e Fraturas em Medicina e Reabilitação. 6. ed. São Paulo: Atheneu, 1996.

ASSOCIAÇÃO BRASILEIRA DE NORMAS TÉCNICAS. NBR ISO 9583: Implantes para cirurgia - Ensaio não-destrutivo - Inspeção por líquido penetrante de implantes cirúrgicos metálicos. Rio de Janeiro, 1997.

BARSOM, J. M. Fracture and Fatigue Control in Structures. São Paulo: PrenticeHall, 1987.

BRASIL. Ministério da Saúde. Agência Nacional de Vigilância Sanitária. Consulta Pública n 24, de 8 de março de 2002. D.O. de 11/03/2002. Brasília. 2002.

CHOHFI, M.; KÖBERLE, G.; REIS, F. B. Prótese Metal/metal: uma tendência? Revista Brasileira de Ortopedia, v. 32, n. 10, p. 760-766, Outubro 1997.

COLANGELO, V. J. Corrosion fatigue in surgical implants, Journal of Basic Engineering, p. 581-5686, December, 1969.

DANDY, D. J. Ortopedia e Traumatologia Prática. 2. ed. Rio de Janeiro: Revinter, 2000 .

FRAKER, A. C.; RUFF, A. W. Metallic surgical implants: state of art. Journal of Metals, p. 22-28, May 1977.

GREVE. J. M. D. Medicina de Reabilitação Aplicada à Ortopedia e Traumatologia. São Paulo: Roca, 1999.

HAMIL, J.; KNUTZEN, K. M. Bases Biomecânicas do Movimento Humano. São Paulo: Manole, 1999. 
INTERNATIONAL ORGANIZATION FOR STANDARDIZATION, Switzerland, ISO 7206-4; Implants for surgery - Partial and total hip joint prostheses - Part 4: Determination of endurance properties of stemmed femoral components with application of torsion. Switzerland, 1989.

INTERNATIONAL ORGANIZATION FOR STANDARDIZATION, Geneve, ISO 5833, Implants for surgery - Acrylic Resin Cements. 1992.

LOPES, G. D. Biodeterioration and corrosion of metallic implants and prosthetic devices. Medicina Buenos Aires. v. 53, n. 3, p. 260-274, 1993.

MARTIN, J. W.; TALBOT, D. E. J. A study or crack initiation in corrosion fatigue of AISI type 316 stainless steel by dynamic measurement of corrosion current transients. Nuclear Technology, v. 55, n. 2, p. 499-504, Nov, 1981

MÜLlER, M. E. Total Hip Reconstruction. Surgery of the Muscoloskeletal System. Churchill Livingstone Inc. 1983.

NIINOMI, M. Fatigue characteristics and microstructure of titanium alloys for biomedical applications. Int. J. Fatigue. vol 34, 2002, p. 2073-2083.

NORMAN, T. L.; KISH, V.; BLAHA, J. D.; GRUEW, T. A.; HOSTOSKY, K. Creep characteristics of Hand an vacuum-mixed acrylic bone cement at elevated stress levels. Jornal of Biomedical Materials Research. v. 29, p. 495-501, 1995.

NORTHFIELD, M. R.; SCHMALZRIED, T. P.; BELCHER, G.; AMSUTZ, H. C. Quantitative assessment of activity in joint replacement patients. Trans Orthop Res Soc. 40:680, 1994

PARIS, P. C.; ERDOGAN, F. A critical analysis of crack propagation laws. Journal of Basic Engineering, Trans. ASME, series D, 55, 528-534, 1963.

RAMANIRAKA, N. A.; RAKOTOMANANA, L. R.; LEYVRAZ, P. F. The fixation of the cemented femoral component. Effects of stem stiffness, cement thickness and toughness of the cement-bone surface. The Journal of Bone and Joint Surgery. v. 82-B n. 2, March 2000. ISSN 0301-620X

ROCKWOOD JR, C. A.; WILKINS, K. E.; KING, R. E. Fratura em crianças. São Paulo: Manole, 1993.

ROSA, S.; BARBOSA, P. F.; BUTTON, S.T.; BERTAZZOLI, R. In-vitro corrosions resistance study of hot worked Ti-6Al-7Nb alloy in a isotonic medium. Brazilian Journal of Chemical Engineering, v. 18, n. 1, p. 47-59, March 2001.

ROSE, R. M.; NUSBAUM, H. J.; SCHEIDER, H. On the true wear rate of ultra hight-molecular-weight polyethylene in total hip prosthesis. The Journal of Bone and Joint Surgery. v. 62: 537-549, 1980.

SCHRÖCK, J. Montagem, Ajuste, Verificação de peças de Máquinas. Rio de Janeiro: Revertè, 1979. 
SHROTRIYA, P.; MERCER, C. Contact fatigue of Biomedical Material. Int. J. Fatigue. v. 34, 2002, p. 2093-2104

SOUZA, A. S. Ensaios Mecânicos de Materiais Metálicos. 3. ed. São Paulo: Edgard Blucher, 1979. p. 172-199.

TEOH, S. H. Fatigue wear of Biomaterials. Int. J. Fatigue. vol. 34, 2002, p. 20612110 .

VAUGHAN, C. L.; BROOKING, G. D. \& OLREE, K. S. Exploring Strategies for Controlling Multiple Muscles in Human Locomotion. Human Motion Analysis -Current Applications and Future Directions., G.F. Harris \& P.A. Smith (orgs.). Nova Iorque. IEE Press, 1996, p. 9-11

VIGORITA, V. J. Orthopaedic Pathology. Philadelphia, Lippincott Williams \& Wilkins, 1999. ISBN 0-7817-0040-X.

VILADOT, R.; COHI, O.; CLAVELl, S. Órtese e Prótese do Aparelho Locomotor. São Paulo: Livraria Santos, 1989.

WILliaMS, D. F. Progress in Biomedical Engineering: Definitions in Biomaterials. v.4 Amsterdam: Elsevier, 1987.

WINTER, D. A. Biomechanics and Motor Control of Human Movement. 2. ed. Nova Iorque: John Wiley \& Sons, 1990. 